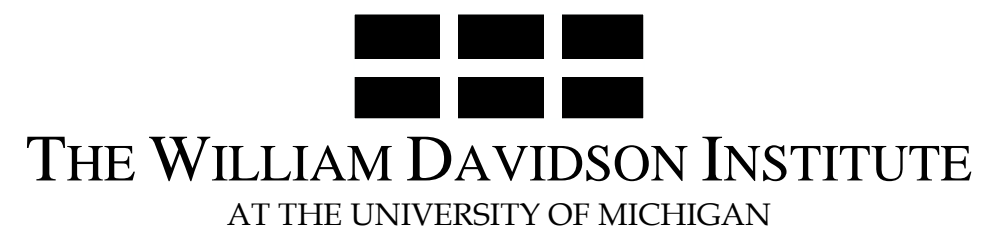

AT THE UNIVERSITY OF MICHIGAN

\title{
Monetary policy rules and inflation process in open emerging economies: evidence for 12 new EU members
}

By: Bořek Vašiček

William Davidson Institute Working Paper Number 968

September 2009 


\title{
Monetary policy rules and inflation process in open emerging economies: evidence for 12 new EU members
}

\author{
Bořek Vašíček ${ }^{*}$ \\ Department of Applied Economics \\ Universitat Autònoma de Barcelona
}

\begin{abstract}
This paper has three objectives. First, it aims at revealing the logic of interest rate setting pursued by monetary authorities of 12 new EU members. Using estimation of an augmented Taylor rule, we find that this setting was not always consistent with the official monetary policy. Second, we seek to shed light on the inflation process of these countries. To this end, we carry out an estimation of an open economy Philips curve (PC). Our main finding is that inflation rates were not only driven by backward persistency but also held a forward-looking component. Finally, we assess the viability of existing monetary arrangements for price stability. The analysis of the conditional inflation variance obtained from GARCH estimation of PC is used for this purpose. We conclude that inflation targeting is preferable to an exchange rate peg because it allowed decreasing the inflation rate and anchored its volatility.
\end{abstract}

Keywords: open emerging economies, CEE countries, monetary policy rules, open economy Phillips curve, conditional inflation variance

JEL Classification: E31, E52, E58, P24

\footnotetext{
* Correspondence Address: Department of Applied Economics, Universitat Autònoma de Barcelona, Edifici B, 08193 Bellaterra (Cerdanyola del Vallès), Spain. E-mail: borek.vasicek@uab.es, borek.vasicek@gmail.com. Tel.: +34-935811680. Fax: +34-935812292. I would like to thank Jan Babecký, Peter Clayes, Matthew Greenwood-Nimmo, Martin Macháček and Kateřina Šmídková for their helpful comments. I am also indebted to the participants of the 5th International Conference - Developments in Economic Theory and Policy (Bilbao), of the International Conference on Monetary and Financial Transformations in the CEECs (Paris), XXXIII Economic Analysis Symposium (Zaragoza) and of an internal seminar at Monetary Policy Stance Division of the European Central Bank. Any remaining errors are mine own. A reduced version of this paper was published in Les Cahiers de Recherche de l'ESCE, No. 11/2009, Paris, pp. 451-476.
} 


\section{Introduction}

This study aims at presenting evidence on the monetary policy rules and sources of the inflation process for open emerging economies, in particular 12 new EU member states (NMS) using a dataset from a recent post-transitional period (1999-2007). Consequently, our principal objectives can be resumed as follows. First, we aim at revealing the logic of interest rate setting pursued by monetary authorities of the NMS. Second, we seek to shed some light on the nature of the inflation process in these countries. Third, we asses the viability of the monetary arrangements of these countries for their domestic price stability.

Twelve NMS (Bulgaria, Cyprus, the Czech Republic, Estonia, Hungary, Malta, Latvia, Lithuania, Poland, Romania, Slovakia, and Slovenia) are rather specific as compared to other emerging economies. ${ }^{1}$ They are small and very open economies. In addition, ten of them share a unique experience of transition from the central planning towards the market economy. The recent EU membership, coupled with the forthcoming adoption of the euro, represents again a unique external condition. In spite of these similarities, the official monetary policy arrangements and the exchange rate regimes pursued in these countries have been very heterogeneous. ${ }^{2}$ Both the similarities of the NMS as compared to other emerging economies and the diversity of their monetary policy arrangements make them an interesting subject of common comparative analysis.

Since the celebrated paper by Taylor (1993), empirical research on monetary policy rules has shown logic in the decision-making process of independent central banks. Most of the empirical evidence (starting with Clarida et al., 1998) has been provided for the major central banks (the FED, Bank of England, Bank of Japan and the ECB). The studies found that the

\footnotetext{
${ }^{1}$ We use in the whole text the following country abbreviations: BUL - Bulgaria, CYP - Cyprus, CZE - the Czech Republic, EST - Estonia, HUN - Hungary, LAT - Latvia, LIT - Lithuania, MAL - Malta, POL - Poland, ROM - Romania, SLO - Slovenia, SVK - Slovakia.

${ }^{2}$ While the Czech Republic and Poland maintained the inflation targeting since 1997 and 1998 respectively, Hungary adopted this framework only in 2001 and Romania in 2005 (before 2005 Romania pursued a version of monetary targeting). Slovakia pursued inflation targeting only implicitly. Slovenia applied a regime with monetary target. All of these countries had relatively flexible exchange rate regimes until Slovakia and Slovenia joined the ERM II in 2005. During our period of analysis (1999-2007) the Romanian leu underwent a currency reform (in 2005) and the central parity of the Slovak koruna within ERM II was readjusted (in 2007) as a consequence of continuing appreciation against the euro. The remaining countries relied on different versions of exchange rate peg. Estonia had a currency board with the euro (originally DEM) and joined ERM II in 2004. Latvia used a currency board with SDR until 2005 when it joined ERM II. The Lithuanian litas was pegged to the US dollar until 2002, when it was switched to the euro and the country joined ERM II in 2004. Cyprus had peg to the euro and Malta to a currency basket, succeeded by ERM II membership in 2005. Finally, Bulgaria still maintains a currency board with the euro (introduced originally in 1997 with the German mark). Markiewicz (2006) analyzes the determinants of the choice of different exchange rate strategies of CEEC.
} 
short-term interest rate setting can be described by a version of the Taylor rule (TR), that suggests that the short-term interest rate responds to (observed or expected) inflation rate and the stance of economic activity (the output gap). The research aimed at emerging economies is scant. Studies focusing on Asian and Latin American countries (Filosa, 2001, Mohanty and Klau, 2007) confirmed that their central banks responded very strongly to exchange rates. In some cases, this response was of higher magnitude than the response to domestic inflation. This does not come as a surprise given that the exchange rates have been highly volatile in some emerging economies, which was often related to severe balance of payment crisis. The reality of emerging economies of Central and Eastern European countries (CEEC) has been different. These countries did not experience similar turbulences and their monetary policy was rather affected by a unique process of economic transition. In addition, they opted recently for EU membership and are expected to adopt the euro in very near future. Therefore, the period where we can link the interest rate decisions to the developments of main macroeconomic variables is quite recent and very short. The estimated monetary policy rule is useful as a unifying framework to compare the (de-facto) monetary policy setting with the official (de-jure) monetary policy regime, which is a certain analogy to focus commonly applied at exchange rate regimes (Frömmel and Schobert, 2006a). However, such analysis rests on strong assumption that the short-term interest rate is exogenous variable set by the central bank. Countries that pursue exchange rate targets may use besides the interest rate also other instruments like the exchange rate interventions, which makes that the interest rate adjusts endogenously.

A few studies aimed to provide evidence on monetary policy rules in NMS. Mohanty and Klau (2007) included three NMS (CZE, POL, HUN) in their larger sample of emerging countries. However, the choice of the estimation period (1995-2002) does not seem to be very reasonable given that CEEC were still strongly affected by the economic transition and monetary policy making was discretional. María-Dolores (2005) provided estimates for four NMS (CZE, POL, HUN, SVK), concluding that their interest rate setting (1998-2003) could be reasonably described by simple TR. However, it is likely that these results are biased due to omitted variables, since the author does not consider any explanatory variable behind inflation and the output gap in his empirical model. ${ }^{3}$ Frömmel and Schobert (2006b) paid attention to a variety of exchange rate regimes during the analyzed period (1994-2005) in the

\footnotetext{
${ }^{3}$ Although no results of autocorrelation test were presented, the reported p-value of Sargan overidentification test that were only slightly higher than 0.05 gives reasons to believe that the model is misspecified due to the omission of relevant regressors.
} 
sample of six NMS. Consequently, they included the exchange rate as additional explanatory variable. The striking result is that the lagged interest rate is often the only significant variable (with coefficient close to unity). This implies that short-term interest rates de-facto followed random walks, which cannot be considered a reasonable description of the monetary policy. ${ }^{4}$

While most empirical studies on monetary policy rules terminate with the presentation of the estimated coefficient we make one step further. Given the prominence of price stability as the central bank implicit or explicit objective, we additionally pursue analysis of the determinants of the inflation process in these countries. The purpose is to see whether differences in monetary policy setting imply specific features of inflation dynamics. The empirical research on the inflation dynamics is again vast for the major economies, mostly within the framework of the New Keynesian Phillips curve (NKPC). This model suggests that expected inflation and marginal cost are the main determinants of current inflation rates (Galí and Gertler, 1999, Galí et al. 2001). Recent studies extended this model to adjust better to the data of open economies (Batini et al., 2005 or Rumler, 2007). The inflation process in the CEEC has several peculiarities. First of all, not long time ago it was still strongly influenced by institutional factors, such as price deregulation. The cross-country studies on inflation dynamics of the NMS are scarce and often focused on narrower issues such as the exchange rate pass-through (ERPT) into domestic prices (Coricelli et al., 2006) or inflation persistence (Franta et al., 2007).

As regards out third objective, there are many empirical studies evaluating the performance of different monetary policy regimes with respect to price stability. The studies aim either at different policy episodes within one country (Kontonicas, 2004) or provide cross-country evidence (Ball and Sheridan, 2003). The results are rather ambiguous as to whether inflation targeting versus or exchange rate peg deliver better outcomes.

Our extensions to previous research are several. First, we present coherent multi-country analysis based on large and recent dataset that allows us to draw some general conclusions and international comparisons. Many countries in our sample have not been subject to similar analysis so far. Second, we study monetary policy and the inflation process together. Our specification of both relations is very general including a wide range of potential explanatory

\footnotetext{
${ }^{4}$ See Appendix for resume of estimates for the NMS.
} 
variables. Third, we evaluate the viability of different monetary policy regimes with the view of achieving the price stability by means of inflation volatility.

The rest of the paper is organized as follows. In next section, we present our econometric framework. In Section 3, we present our dataset and the results of the basic time series analysis. Section 4 reviews the estimates of monetary policy rules. Results on the inference of the inflation process properties and the evaluation of the viability of present policy rules for the price stability are reported in Section 5 and 6. The last section concludes.

\section{Econometric framework}

\subsection{Monetary policy rules}

Taylor (1993) made a pioneer contribution to the modeling of monetary policy decisions of central banks. He proposed that the FED setting of the federal fund rate can be tracked as a simple function of the observed inflation rate (gap) and the stance of the real economic activity. Such interest rate rule can be written as:

$$
i_{t}^{*}=\bar{i}+\beta\left(\pi_{t}-\pi^{*}\right)+\gamma y_{t}+\varepsilon_{t}
$$

where $i_{t}^{*}$ is the short-term interest rate target, $\bar{i}$ is the nominal equilibrium interest rate (consisting of the real equilibrium interest rate and the inflation target $\pi^{*}$ ), $\pi_{t}$ is the inflation rate, $y_{t}$ is the output gap and $\varepsilon_{t}$ is the error term. ${ }^{5}$ Clarida et al. $(1998,2000)$ suggested that some right-hand side variables of the equation (1) should enter as expected future values. This usually applies to the inflation rate since many central banks, especially those using direct inflation targeting (DIT), set interest rates with respect to inflation forecast than a current inflation rate. Consequently, the right-hand side variables enter under expectation $E$ formed on the basis of available information $\Omega_{\uparrow}$ :

$$
i_{t}^{*}=\bar{i}+\beta\left(E\left[\pi_{t+s} \mid \Omega_{t}\right]-\pi_{t+s}^{*}\right)+\gamma\left(E\left[y_{t+k} \mid \Omega_{t}\right]\right)+\delta\left(E\left[x_{t+m} \mid \Omega_{t}\right]\right)+\varepsilon_{t}
$$

This specification also includes additional variables $x_{t}$ that can potentially affect the interest rate setting. Unfortunately, the data on past expectations of monetary authorities are hardly available. Therefore, the expected values of variables are commonly substituted by their actual realizations. This strategy introduces endogeneity into the empirical model as the

\footnotetext{
${ }^{5}$ The empirical studies mostly use the inflation rate as regressor instead of the inflation gap (difference between the inflation rate and its target). This is because the inflation target is not explicitly defined in many countries. As long as it is constant over the estimation period, the use of the inflation rate does not alter the estimation results.
} 
disturbance term $\varepsilon_{t}$ now includes a prediction error $E\left[\pi_{t+s} \mid \Omega_{t}\right]-\pi_{t+s}$ and as such is correlated with the regressor $\pi_{t+s}$. The instrumental variables (IV) estimators are needed to deal with this issue. Finally, most central banks smooth the interest rate changes over time as not to have any disruptive effects on economy. Such policy inertia can be described by partial adjustment mechanism:

$$
i_{t}=\rho i_{t-1}+(1-\rho) i_{t}^{*}+v_{t}
$$

where the actual short-term interest rate $i_{t}$ is a combination of the interest rate target $i_{t}^{*}$, implied from the policy rule, and the lagged value (usually one period) of the interest rate $i_{t-1}$ ( $\rho$ expresses the intensity of smoothing). Following this practice we can write our empirical model used for the estimation of monetary policy rules as a combination of equations (2) and (3):

$$
i_{t}=\rho i_{t-1}+(1-\rho)\left(\alpha+\beta \pi_{t+s}+\gamma y_{t+k}+\delta x_{t+m}\right)+v_{t}
$$

where all the variables have the previous meaning, $\alpha$ is a constant term and the additional variables $x_{t+m}$ are those proposed in different studies and: the foreign interest rate, the longterm interest rate, the exchange rate, monetary growth, and asset prices. It is evident that some of these variables can be highly relevant for small open economies. According to the equation (4), the policy can be either backward- or forward-looking as all the sub-indices can take positive or negative value. We use one period lagged inflation in case of backward-looking rule $(s=-1)$ and one period ahead inflation $(s=1)$ in case of forward-looking specification. ${ }^{6}$ The output gap always enters in a present or a past value $(k \leq 0)$ alike the additional variables $(m \leq 0){ }^{7}$ Because the error term $v_{t}$ is a linear combination of forecast errors of the right-hand side variables and the original exogenous disturbance $\varepsilon_{t}$, it shall be orthogonal to the present information set $\Omega_{t}$, which can be exploited as moment condition:

$$
v_{t}=-(1-\rho)\left\{\beta\left(\pi_{t+s}-E\left[\pi_{t+s} \mid \Omega_{t}\right]\right)+\gamma\left(y_{t+k}-E\left[y_{t+k} \mid \Omega_{t}\right]\right)+\delta\left(x_{t+m}-E\left[x_{t+m} \mid \Omega_{t}\right]\right)\right\}+\varepsilon_{t}(5)
$$

We estimate different versions of the model (4) by means of Generalized Method of Moments (GMM). Two lags of endogenous and exogenous variables of each specification are used as

\footnotetext{
${ }^{6}$ To avoid the problem of weak instruments in GMM framework, we use only one lead of inflation rate in the forward-looking specification even though the forecasting/targeting horizon is usually 1-2 years. Moreover, the prediction error (difference between inflation expectation and its actual future realization) increase in longer horizon.

${ }^{7}$ We instrument all the regressors with their lagged values since many of them are rather predeterminated than strictly exogenous.
} 
IV. ${ }^{8}$ The GMM weighting matrix was chosen in accordance with the Newey and West (1994) covariance estimator, which is robust to the presence of both heteroskedasticity and autocorrelation of unknown form (HAC Consistent Covariances). The correlation in moment conditions was soaked up by means of previous VAR(1) estimation for IV (pre-whitening).

\subsection{Inflation process in open economies}

The predominant New Keynesian literature disregards a traditional backward-looking PC in favor of a forward-looking PC derived from a model of price-setting behavior of monopolistically competitive firms. The empirical NKPC can be written as:

$$
\pi_{t}=\beta E\left[\pi_{t+1} \mid \Omega_{t}\right]+\gamma m c_{t}+u_{t}
$$

where the current inflation rate $\pi_{t}$ depends on its expected value pursuant to the rational expectations of the economic agents (based on the information set $\Omega_{t}$ ) and on marginal cost $m c_{t}$ that is deemed to be the main inflation-forcing variable. However, this model was found to be at odds with data. First, it does not account for the inflation persistence. Second, the marginal cost is an unobservable variable that must be proxied, typically by unit labor cost. Such measure of marginal cost may not be sufficiently representative for small economies that import significant part of intermediate inputs. More importantly, the inflation rates in small economies may have numerous external determinants unrelated to price setting of domestic firms. Therefore, to model inflation dynamics, we depart from a hybrid NKPC where current inflation rate depends on both its previous value and expectation of future value (Fuhrer and Moore, 1995, Galí and Gertler, 1999): ${ }^{9}$

$$
\pi_{t}=(1-\beta) \pi_{t-1}+\beta E\left[\pi_{t+1} \mid \Omega_{t}\right]+\gamma y_{t}+u_{t}
$$

Given the controversy about the marginal cost $m c_{t}$, we use a traditional cyclical measure of the economic activity - the output gap $y_{t}$. We include into the model additional variables that can have effect on inflation of open economies. Svensson (2000) derived the NKPC for open economy augmented by the exchange rate. ${ }^{10}$ Empirical studies aimed at the quantification of the ERPT into domestic prices (Gagnon and Ihrig, 2004, Campa and Goldberg, 2005, Coricelli et al., 2006) employed a similar inflation equation with two additional variables

\footnotetext{
${ }^{8}$ Mavroeidis (2005) showed that the practice of including too many lags of IV leads to a debilitation of the Sargan-Hansen test for overidentifying restrictions. Two lags allow performing the test without significant distortion of its power.

${ }^{9}$ Galí and Gertler (1999) derived this hybrid PC in a framework where part of the firms set prices by means of backward-looking rule of thumb.

${ }^{10}$ Batini et al. (2005) used NKPC augmented by variables of foreign competition, relative prices of imports and oil prices for the empirical analysis of the UK inflation.
} 
accompanying the exchange rate. First, the foreign inflation rate represents a direct transmission of foreign prices to domestic ones. Second, the lagged domestic interest rate tracks the effect of domestic monetary policy. ${ }^{11}$ Accordingly, we use general specification that takes into account all these possible determinants of inflation dynamics:

$$
\pi_{t}=\alpha+\beta_{1} \pi_{t-1}+\beta_{2} \pi_{t+1}^{\exp }+\gamma y_{t-1}+\delta \pi_{t}^{f o r}+\eta s_{t-1}+\mu i_{t-4}+u_{t}
$$

where $\alpha$ is an intercept representing variables having constant effect on the inflation rate. ${ }^{12}$ Unlike most empirical NK literature, we do not impose that the coefficients of the backwardlooking term $\pi_{t-1}$ and the forward-looking term $\pi_{t+1}^{\exp }$ sum up to unity. ${ }^{13}$ The exogenous variables that can driven inflation are the output gap $y_{t-1}$, the foreign inflation rate $\pi_{t}^{\text {for }}$, the exchange rate $s_{t-1}$ and the domestic interest rate $i_{t-4}$. The lag of the output gap is set to one as in a standard PC. The interest rate enters with four lags since the horizon of the monetary transmission is around one year. The exchange rate enters with one or two lags pursuant to the VAR studies confirming that the ERPT has the strongest effect within one or two quarters.

The model specification brings about some econometric complications. The main issue is related to the forward-looking inflation term. Because inflation expectations are typically not available, they must be proxied by realized values of inflation. The IV should be employed to deal with the endogeneity that arise in the same fashion as in the forward-looking policy rule. Moreover, multicollinearity can arise if the backward- and forward-looking inflation terms are strongly correlated. To deal with both problems, we proxy the expected inflation $\pi_{t+1}^{\exp }$ by oneperiod-ahead inflation gap. This variable is constructed as a deviation of inflation in $t+1$ from its trend value obtained by Hodrick-Prescott filter. The multicollinearity is avoided since the correlation of this inflation gap with one lag of inflation rate is not very strong. The use of inflation gap in $t+1$ also deals with potential endogeneity because it is de facto an IV for onelead of inflation. It is very strongly correlated with inflation in $t+1$ but not necessary with the error term. If endogeneity does not arise, then OLS and GMM must provide reasonably similar estimates. We use OLS as a benchmark and GMM for a robustness check. An important advantage of OLS is that it can be simply extended to ARCH model that allows capturing the time-varying volatility potentially present in inflation series. In particular, we

\footnotetext{
${ }^{11}$ These studies use VAR methods as they are interested in the temporal dimension of the ERPT to domestic prices. The forward-looking inflation component is not included since the VAR methodology is not suitable to deal with the issues of endogeneity.

${ }^{12}$ The presence of the intercept is relevant especially for the estimation in the panel setting, where it represents the country fixed-effect.

${ }^{13}$ This condition assures that there is no trade-off between inflation and output in the long-term.
} 
use the most general and common model of volatility, GARCH $(1,1)$. The corresponding variance equation can be written as:

$$
\sigma_{t}^{2}=\omega+v_{1} \xi_{t-1}^{2}+v_{2} \sigma_{t-1}^{2}
$$

where $\sigma_{t}^{2}$ is the conditional variance (one-period ahead forecast variance), the constant term

$\omega$ is the long-term variance, $\xi_{t-1}^{2}$ is the $\mathrm{ARCH}$ term (the squared residuals from the last period) representing the impact of new information about volatility from the last period, and $\sigma_{t-1}^{2}$ is the GARCH term representing the impact of the forecast variance from the last period. The GARCH estimates of the PC parameters are not only more efficient than OLS in case of conditional heteroskedasticity but this framework also allows obtaining estimates of the conditional variance $\sigma_{t}^{2}$. The conditional variance of inflation can be used apart from the inflation level as another measure of the price stability. Highly volatile inflation strengthens the inflation expectations of private agents, which according to the NKPC drive up current inflation rate. Therefore, the estimates of the variance equation and the implied conditional variance series may shed some light on the viability of existing monetary policy.

\section{Data and time series analysis}

\subsection{Data description}

Our dataset consists of quarterly data ranging from 1999/1.Q till 2007/4.Q. The series are slightly shorter for some variables or countries but in all cases, they cover at least 8 years. The principal data source is Eurostat (inflation rate, GDP, industrial production, exchange rate, monetary aggregate M3, share index, interest rates). Missing data for some countries were obtained from national central banks (long-term interest rates).

The short-term interest rate is the 3-month interbank interest rate. The overnight interbank interest rate is used for a robustness check in the policy rule estimation. The foreign interest rate (used in an augmented policy rule) is represented by 3-month EURIBOR (EONIA is used for a robustness check). The inflation rate is measured as a yearly change in the harmonized consumer price index (HCPI, 2005 is the base year). ${ }^{14}$ The foreign inflation rate (used in an open economy PC) is a yearly change in the HCPI of the Euro area. The long-term interest rate is measured by 10-year government bond yield. The output gap is a difference between the logarithm of the current value of the seasonally adjusted GDP (in millions of euros in 
1995 prices) and the trend value obtained by Hodrick-Prescott filter (the smoothing parameter set to 1600). ${ }^{15}$ The industrial production index is used for a robustness check in the monetary policy rule estimation. The exchange rate is the real effective exchange rate index (REER, against 12 main trading partners, deflated by CPI, 1999 is the base year) and the nominal exchange rate against the euro (in unit of euros for a unit of domestic currency). ${ }^{16} \mathrm{~A}$ yearly change of the exchange rate is used for the estimation and its deviation from HP trend for a robustness check. The monetary growth is proxied by a yearly change in the seasonally adjusted M3 aggregate (in national currency, common definition by Eurostat). Asset prices are proxied by the share index of local stock exchange (rebased for all countries to $2001=100$ ), whose yearly change is used. ${ }^{17}$

\subsection{Time series analysis}

The time series used for the empirical analysis are subject to thorough unit root testing (ADF, PP, KPSS tests). The stationary is confirmed for all variables besides the inflation rates and the interest rates. These findings lead us to test whether the nonstationary variables are cointegrated. The cointegration is tested by means of Augmented Engle-Granger (AEG) test (Engle and Granger, 1987), which is ADF tests of unit root applied at residuals of the auxiliary regression with nonstationary variables. The cointegrating vector in case of monetary policy rule usually consists of the short-term interest rate, the inflation rate (DIT countries) and/or the foreign interest rate (some DIT countries and countries with exchange rate pegs). In term of the Phillips curve, we find cointegrating relation between the inflation rate, the foreign inflation rate and the lagged interest rate. In a few cases when cointegration is rejected, we use first differences of variables for the regression (variables in the policy rule for CYP and LAT). ${ }^{18}$

\footnotetext{
${ }^{14}$ Although CPI inflation is more relevant both for monetary authority and for private agents, HCPI is strongly correlated with CPI and is a comparable measure for all countries in the sample.

${ }^{15}$ The limits of HP filter for identification of the output gap are well known. However, given the sample of the countries, we are unable to employ additional methods.

${ }^{16}$ An increase means appreciation as so to be consistent with the REER, whose increase means appreciation.

${ }^{17}$ There are two controversies related to asset prices in empirical analysis of monetary policy rules. First, what is correct measure of asset prices? In particular, whether is the share index sufficiently representative or whether the housing prices should be included as well. Second, how to measure the misalignment in asset prices given the difficulties to estimate their equilibrium value. The latter problem can be even more pronounced for posttransitional economies of the NMS.

${ }^{18}$ The results reported in Appendix. There are several limitations of the AEG test. First, note that lagged values of the dependent variable had to be included in the cointegrating regression as to obtain I( 0$)$ residuals. This is rather problematic because the omission of the short-term dynamics shall not alter the results if the I(1) variables are cointegrated. However, note that AEG tests relies on ADF testing (with specific critical values, e.g. Davidson and MacKinnon, 1993) of the residuals from an auxiliary regression with I(1) variables. Given the size of our sample, the low power of the single-equation ADF test may affect the AEG test results as well. Second, the critical values are very sensitive to presence of heteroscedaticity and autocorrelation in the data. Third, the power
} 
It has become common to include the foreign interest rate (of dominant economy) as an additional regressor in estimated policy rules (Clarida et al., 1998). However, even thought the short-term interest rates of most NMS are highly correlated with the interest rates in the Euro area it does not automatically imply any causal relationship. For this reason, we apply the Granger causality test. In particular, we test whether the lagged values of the euro shortterm interest rate provide any additional information about the present values of the shortterm interest rate of each NMS while the reversed causality is not present. ${ }^{19}$ The results are the following: we cannot reject (at 5\% significance level) that the euro short-term interest rate caused the short-term interest rate of Bulgaria, the Czech Republic, Estonia, Latvia, Lithuania, Malta and Slovakia. While the influence of the ECB interest rate setting is expected to be found for countries with exchange rate pegs to the euro, it is an interesting finding for countries maintaining a flexible exchange rate.

The causality is also puzzling in case of the relationship between the short-term and the longterm interest rates. They are correlated in all countries but the causal relationship is not selfevident, in fact, it may even run from the short- to long-term interest rate as long as the latter are determined as expected future short-term interest rate. Mehra (2001) argued that the longterm interest rate carries information about inflation expectations and should be included as an explanatory variable in the estimated monetary policy rule. For this reason, we test whether the long-term interest rate Granger-caused the short-term interest rate. This causality is not rejected for the Czech Republic, Estonia and Slovakia. Although this test has various limitations, we consider its results as a preliminary indication of whether the foreign shortterm interest rates and the domestic long-term interest rate could give any information about short-term interest rate setting in the NMS.

\section{Empirical evidence on the monetary policy rules in the NMS}

To begin, we have fitted the generic form of the Taylor rule as a benchmark. These results are reported in Table 1. We can see that this simple policy rule does not hold for any country in

of the test weakens if the data are seasonally adjusted. Finally, the results of the AEG test are sensitive to normalization; in particular switching between dependent and explanatory variables in the cointegrating regression implies different residuals. However, in spite of these limitations the AEG test is the best suited for our empirical framework, which is single equation with simple dynamics. We also employ maximum likelihood test of Johanssen (1991) allowing for more than one cointegrating relationships. This test confirmed in all cases our previous results. The error-correction model (ECM) allows testing cointegration together with the estimation of the empirical model. However, the use of the ECM is unfeasible given that we have many possible explanatory variables (and therefore various potential cointegrating relations) and we have to deal with other issues like endogeneity. 
our sample. Although the inflation coefficient is positive and significant in some cases, the overall fit of the model is very low. Moreover, a simple inspection of the Durbin-Watson statistics points to serial correlation, possibly due to model misspecification. This is not surprising, given that all these countries are small open economies, where various constraints condition the interest rate setting. In addition, this specification does not take into account that monetary policy authorities may be rather forward-looking and smooth its actions over time. ${ }^{20}$ In any case, these results point that if any systematic interest rate setting existed, it differed across the countries. This does not come as a surprise given diversity of official monetary and exchange rate arrangements in the NMS.

Table 1.: OLS estimates of backward-looking TR

\begin{tabular}{llllllllll}
\hline Country & \multicolumn{2}{c}{$\boldsymbol{\alpha}$ (const.) } & \multicolumn{2}{c}{$\boldsymbol{\beta}\left(\boldsymbol{\pi}_{\mathrm{t}-1}\right)$} & \multicolumn{2}{c}{$\boldsymbol{\gamma}\left(\mathrm{y}_{\mathrm{t}-1}\right)$} & $\mathbf{R}^{2}$ & $\mathbf{D W}$ \\
\hline BUL & $\mathbf{3 . 7 4}$ & $(0.27)$ & $\mathbf{0 . 1 1}$ & $(0.04)$ & -0.33 & $(0.26)$ & 0.12 & 1.07 \\
CYP & $\mathbf{4 . 6 2}$ & $(0.43)$ & 0.05 & $(0.14)$ & $\mathbf{0 . 5 6}$ & $(0.16)$ & 0.18 & 0.16 \\
CZE & $\mathbf{1 . 7 5}$ & $(0.27)$ & $\mathbf{0 . 7 7}$ & $(0.09)$ & -0.44 & $(0.25)$ & 0.46 & 0.22 \\
EST & $\mathbf{1 . 6 7}$ & $(0.83)$ & $\mathbf{0 . 6 4}$ & $(0.25)$ & -0.23 & $(0.17)$ & 0.19 & 0.35 \\
HUN & $\mathbf{4 . 9 8}$ & $(0.71)$ & $\mathbf{0 . 6 7}$ & $(0.10)$ & -0.27 & $(0.76)$ & 0.53 & 0.47 \\
LAT & $\mathbf{6 . 1 2}$ & $(0.63)$ & -0.07 & $(0.14)$ & $\mathbf{0 . 8 1}$ & $(0.20)$ & 0.29 & 0.51 \\
LIT & $\mathbf{4 . 5 7}$ & $(0.61)$ & 0.27 & $(0.17)$ & -0.61 & $(0.59)$ & 0.06 & 0.38 \\
MAL & $\mathbf{3 . 7 5}$ & $(0.21)$ & 0.04 & $(0.09)$ & $\mathbf{0 . 2 6}$ & $(0.09)$ & 0.23 & 0.37 \\
POL & $\mathbf{2 . 9 6}$ & $(0.54)$ & $\mathbf{1 . 5 8}$ & $(0.15)$ & -0.08 & $(0.35)$ & 0.86 & 0.56 \\
ROM & -0.14 & $(1.91)$ & $\mathbf{1 . 2 3}$ & $(0.15)$ & -0.54 & $(1.36)$ & 0.75 & 0.49 \\
SLO & $\mathbf{2 . 0 8}$ & $(0.67)$ & $\mathbf{0 . 9 0}$ & $(0.10)$ & $\mathbf{0 . 7 8}$ & $(0.31)$ & 0.91 & 0.56 \\
SVK & $\mathbf{3 . 7 9}$ & $(0.80)$ & $\mathbf{0 . 5 4}$ & $(0.13)$ & 1.10 & $(0.60)$ & 0.27 & 0.22 \\
\hline
\end{tabular}

Notes: Standard errors in parenthesis. Coefficients statistically significant at $5 \%$ in bold. DW is Durbin-Watson statistic.

The GMM estimates of the monetary policy rule (specification (4)) with the highest explanatory power are reported in Table $2 .^{21}$ The countries in the upper block maintained a flexible exchange rate during most of the analyzed period, the countries in the lower block used hard exchange rates pegs.

Table 2.: GMM estimates of the monetary policy rule with the highest explanatory power for each NMS

\begin{tabular}{|c|c|c|c|c|c|c|c|c|c|}
\hline Country & $\underset{\left(\mathrm{i}_{\mathrm{t}-1}\right)}{\boldsymbol{\rho}}$ & $\begin{array}{c}(1-\rho) \alpha \\
\text { (const.) }\end{array}$ & $\begin{array}{c}(1-\rho) \boldsymbol{\beta} \\
\left(\pi_{\mathrm{t}-1}, \pi_{\mathrm{t}+1} *\right)\end{array}$ & $\begin{array}{c}(1-\rho) \gamma \\
\left(\mathrm{y}_{\mathrm{t}-1}\right)\end{array}$ & $\begin{array}{c}(1-\rho) \delta \\
\left.\mathrm{f}^{\prime} \mathrm{f}_{\mathrm{t}-1}, \mathrm{i}_{\mathrm{t}} *\right)\end{array}$ & $\begin{array}{c}(1-\rho) \zeta \\
\left(\mathrm{x}_{\mathrm{t}-1}, \mathrm{x}_{\mathrm{t}}^{*}\right)\end{array}$ & $\mathbf{R}^{2}$ & LB & $\begin{array}{c}\text { J- } \\
\text { stat. }\end{array}$ \\
\hline
\end{tabular}

\footnotetext{
19 The test results are reported in Appendix.

${ }^{20}$ These basic result were confirmed when we have used the output gap derived from industrial production (instead of GDP) and overnight interest rate (instead of 3 month interest rates).

${ }^{21}$ Note again that all the specifications were first estimated in levels. I(1) variables in the best adjusting specifications were tested for the cointegration. No reasonable cointegrating relation was found for Cyprus and Latvia. The results for Cyprus come from estimation in first differences. We do not find any well-specified model for Latvia and therefore do not report any estimates for this country. The detailed results for each country are reported in Appendix.
} 


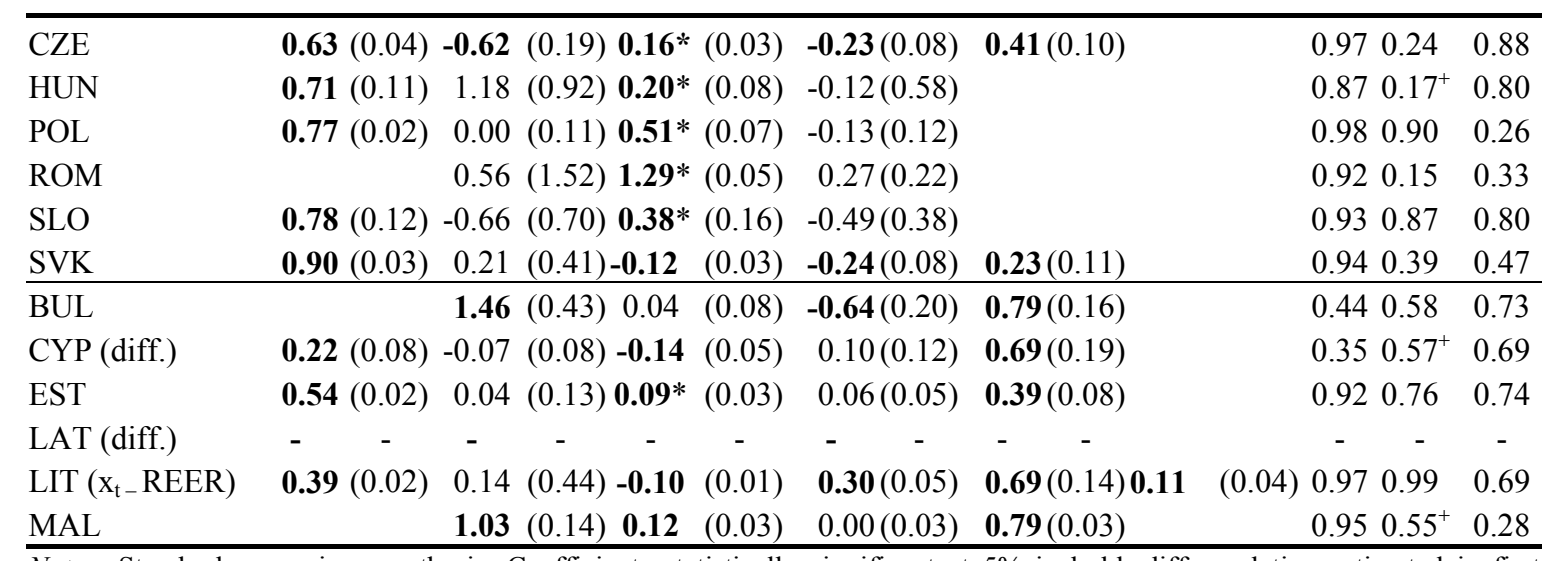

Notes: Standard errors in parenthesis. Coefficients statistically significant at $5 \%$ in bold. diff - relation estimated in first differences, otherwise in levels. $x_{t}-$ REER - additional variable is the real effective exchange rate. LB is p-value of Ljung-Box test for 1 . order serial correlation $\left(^{+}\right.$indicated result after correction $\mathrm{AR}(1)$ in residuals). J-stat is p-value of Sargan overidentification test.

The specifications of policy rules with the highest explanatory power for the DIT countries (CZE, HUN, POL, ROM) are all forward-looking. This seems logical since the inflation forecast is used as an intermediate policy target under the DIT. The long-term inflation multiplier (estimated short-term coefficient adjusted for the interest rate smoothing) exceeds unity for Poland and Romania but not for the Czech Republic and Hungary. The Taylor principle proposes that the monetary policy is stabilizing only if the nominal interest rate is increased by a larger amount than the inflation rate in order to increase the real interest rate. This means that the long-term inflation multiplier $\beta$ should be higher than unity (Clarida et al., 2000). However, the interpretation for small open economies is less straightforward given additional variables affecting the interest rate setting (Linnemann and Schabert, 2006). For instance, for the Czech Republic we find that the short-term interest rate adjusted not only to the expected inflation rate but also to the interest rate in the Euro area. ${ }^{22}$ The latter response can be interpreted as an additional anti-inflationist policy in so much the Czech inflation rate covariated with inflation in the Euro area. ${ }^{23}$ The estimated policy rules of Hungary, Poland and Romania is consistent with the official policy regime - the inflation targeting - aimed solely at domestic price stability. The results for Slovenia resemble the rules of previous countries, although Slovenia did not officially adopt the DIT. The specification with the highest explanatory power is clearly forward-looking in inflation, with long-term coefficient

\footnotetext{
${ }^{22}$ Let us recall that there is Granger causality running from the euro interest rate to the Czech one and the euro interest rate enters the cointegrating vector.

${ }^{23}$ The correlation coefficient of the Czech inflation rate with the average inflation rate in the Euro area is around 0.5. Part of the response of the Czech interest rate to the euro interest rate may be in effect response to domestic inflation. This hypothesis is confirmed when we instead of the euro interest rate include the residual of regression of the euro interest rate on the Czech inflation rate. Such residual represents the euro interest rate
} 
close to unity. At the same time, we reject any response to the euro interest rate. In fact, the euro interest rate was neither part of the cointegrating vector nor Granger-caused the Slovenian interest rate. This finding is surprising because even though Slovenia officially pursued a managed floating, the exchange rate of the Slovenian tolar and the euro was relatively stable during most of the sample period. ${ }^{24}$ The insignificance of the monetary growth is also counter-intuitive, given that the Central Bank of Slovenia officially announced monetary targets. Yet, for the sake of cross-country comparability, we use only yearly change in the monetary aggregate M3 rather than its deviation from specific target value. Slovakia is an opposite case since it claimed to pursue the DIT but we cannot detect a positive and significant response to domestic inflation (it is even negative in the best-adjusting specification). On the other hand, we find a very strong response to the euro interest rate. ${ }^{25}$ One possible explanation can be that the inflation targeting in Slovakia was only implicit and the central bank exercised a lot of discretion. According to our results, it tried to mimic the euro interest rate. It is in fact in line with the Slovak national bank official stance that the DIT was implemented as a tool of convergence to the Euro area.

The policy rules estimates obtained for countries that maintained a fixed exchange rate regimes feature a lack of autonomous monetary policy aimed at domestic macroeconomic developments. The principal variable driving the domestic interest rate is the euro interest rate. Above this, we detect a positive response to domestic inflation in Estonia and Malta and to the real effective exchange rate in Lithuania. Latvia is the only country in the sample where we fail to identify any consistent interest rate rule. It can indicate that the central bank did not apply any systematic interest rate setting but also that short-term interest rate endogenously adjusted to exchange rate interventions aimed at exchange rate stabilization. Moreover, the Latvian interest rate was rather flat during the analyzed period making the monetary policy rule regression unfeasible. The policy rule estimates obtained for these countries can be interpreted that exchange rate fixing was implemented by means of an interest rate peg. This finding goes against the argument of Obstfeld and Rogoff (1996) that interest rate fixing

variance unrelated to Czech inflation rate. While the coefficient of this residual is the same as the previous coefficient of the euro interest rate, the long-term multiplier of the inflation forecast increase to unity.

${ }^{24}$ The statistical insignificance of the euro interest rate can be also related to the multicollinearity between lagged interest rate and the euro interest rate (correlation coefficient 0.83 ). Because the domestic interest rate was almost perfectly correlated with the inflation rate (coef. 0.95), the multicollinearity between the euro interest rates and the domestic inflation (coef. 0.83) also arise here. When we similarly as in Czech case remove the variance of the euro interest rate related to Slovenia inflation rate, the residual enters the estimated policy rule with positive sign and is significant at $10 \%$.

${ }^{25}$ The importance of the euro interest rate for the Slovak interest rate setting is again confirmed by Granger causality test and cointegration test. 
cannot guarantee interest rate peg, which was recently questioned by Benigno et al. (2007). However, it is important to bear in mind that our framework does not allow distinguishing between exogenous and endogenous changes of the short-term interest rate.

The results obtained for the NMS feature some general differences as compared to the evidence established for developed countries. First, the importance of the output gap (coefficient $\gamma$ ) is smaller. A possible explanation can be that that neither the DIT nor policy of an exchange rate peg left room for the output stabilization. Nevertheless, the estimated coefficients of the output gap can be also downwardly biased as the output gap is usually estimated with a lot of noise. This problem can be more pronounced for emerging countries since their supply and demand shocks are of higher magnitude, making the output gap estimates imprecise. Second, the interest rate smoothing parameter is generally smaller than found for developed countries. This can mean that fast and strong response of the interest rate is chosen as make monetary policy more credible in emerging countries. A notable example is Romania, where the monetary policy does not even seem to smooth the interest rate. Third, other variables (the long-term interest rate, asset prices, monetary growth, and the exchange rate) that were deemed to be relevant for explanation of short-term interest rate dynamics in developed countries proved to have negligible impact in the NMS. ${ }^{26}$ Why this can be so? In case of the long-term interest rate, it may be because it reflects more country's sovereign risk than expected inflation. The central bank could be interested in stabilizing it if the risk premium was very variable or if the country's public sector was highly indebted. Yet, none of these applies to the NMS. The negligence of asset prices developments can be linked to a simple fact that assets, in particular stocks, represent a smaller part of household holdings and are thus less important for policy decisions. Moreover, their variability is usually higher, which would imply too much interest rate volatility if the central bank decided to respond to them. However, it is also possible that the response was asymmetric, i.e. that the monetary authorities consider them only when their misalignment exceeded certain threshold. As for the possible effect of housing price on monetary policy that was not considered here, it was found both for developed countries and the CEEC that housing prices evolve closely with other variables like the GDP or real wages (Égert and Mihaljek, 2008). Therefore, housing prices may not provide additional information for monetary policy above the other variables. Moreover, most studies report that housing prices are endogenous to monetary policy stance

\footnotetext{
${ }^{26}$ Some of the coefficients are significant but have only marginal size. However, inclusion of these variables mostly does not improve the fit of the model. See Appendix for detailed results.
} 
given their strong response to real interest rates (Terrones and Otrok, 2004). The omission of monetary developments as relevant information for monetary policy is consistent with the findings for developed countries. Finally, the lack of any consideration of exchange rate developments for interest rates setting is rather surprising given that the NMS are very open economies. There are several possible explanations for this finding. First of all, the exchange rate is logically not an interesting variable in countries maintaining exchange rate peg. On the contrary, the DIT countries may face a trade-off between domestic inflation objective and exchange rate stabilization. However, the exchange rate impact on domestic interest rate can be present implicitly. (a) It can be hidden in the response of domestic interest rate to the foreign interest rate. $^{27}$ (b) The exchange rate changes can be completely passed-through to domestic prices. Consequently, a central bank responding to the CPI inflation implicitly considers the exchange rate as well (Svensson, 2000). (c) The ERPT into domestic prices can be, instead, very limited and a monetary policy authority aimed at domestic price stability does not have to consider the exchange rate developments at all. This claim seems to be justified by studies showing that the ERPT was endogenously restrained by low inflation environment promoted by DIT (Taylor, 2000). (d) A direct response to exchange rate may be feasible strategy for DIT countries if they were to miss the inflation target due to strong currency depreciation. ${ }^{28}$ However, as the NMS were not exposed to this danger unlike some other emerging countries using the DIT (Brazil, South Africa). (e) Taylor (2001) argues that the interest rate response to (real) exchange rate can be only temporal. The interest rate can be decreased following exchange rate appreciation in order to support the domestic exports. However, as domestic currency weakens the interest rate may be increased again to face the imported inflation. Given that we use quarterly data, these two effects may cancel out within the same period and they are not detected in our regression.

The specification with the highest explanatory power for each country was subject to series of robustness checks. ${ }^{29}$ (a) The overnight interbank interest rate is used as dependent variable instead of 3-month interbank interest rate. The fit of such specification is worse in most cases. The dynamics of overnight interest rates reflects, in fact, more the liquidity conditions in the

\footnotetext{
${ }^{27}$ The logic is the following; the increase of foreign interest rate should lead in case of international capital arbitrage to depreciation of domestic currency. Yet, when the domestic monetary policy follows the foreign interest rate setting, this does not happen. Therefore, increasing domestic interest rate in response to foreign interest rate increase is a substitute for interest rate increase that would have to follow the depreciation of domestic currency.

${ }^{28}$ Mohanty and Klau (2007) found a direct response of the interest rate to the exchange rate in emerging economies with significant exchange rate volatility.

${ }^{29}$ These results are not reported here and are available upon request.
} 
banking sector than the macroeconomic fundamentals. Consequently, this variable may not be viable as a measure of policy stance. ${ }^{30}$ (b) We include the inflation gap (deviation of actual inflation rate from the trend value obtained by HP filter) instead of inflation rate for the subsample of countries where we find convincing evidence on the response to inflation (CZE, HUN, POL, ROM, SLO). The trend value is meant to proxy the inflation target by a smoothed series. The gap is consequently the deviation of actual interest rate from the (time-varying) target. The inflation gap is significant only in the case of the Czech Republic. ${ }^{31}$ (c) We use the output gap calculated from the industrial production instead of GDP series. Given that the correlation between the two measures of output gap has been very high in all but two countries (Slovakia - correlation coefficient 0.3 and Cyprus -0.2), the previous results are not altered. Unfortunately, it is above the extent of this study apply alternative methods of the output gap estimation. (d) We use the deviation from the HP trend value of the exchange rate instead of its yearly change. Although the corresponding coefficient turns significant in some cases, its size is unreasonable and the overall fit of the model is always worse.

The estimates reported in Table 2 allows us to perform a counterfactual experiment by comparing the actual interest rate with the implied interest rate path (in-sample forecast from the specification with the highest explanatory power) and use the deviation of these two series as indication of monetary policy shocks. ${ }^{32}$ These results are reported in Figure 1.

\footnotetext{
${ }^{30}$ While the Granger causality of 3-month EURIBOR on domestic 3-month interest rates was confirmed for several countries in the sample, the Granger causality of EONIA on domestic overnight interest rate was found only for the Czech Republic.

${ }^{31}$ The inflation gap is very strongly correlated with inflation rate for the Czech Republic (0.9) but very weakly for Romania (0.3). The other countries have intermediate level of correlation (0.6).

32 The residual can be interpreted as a shock only if the empirical model is correctly specified.
} 

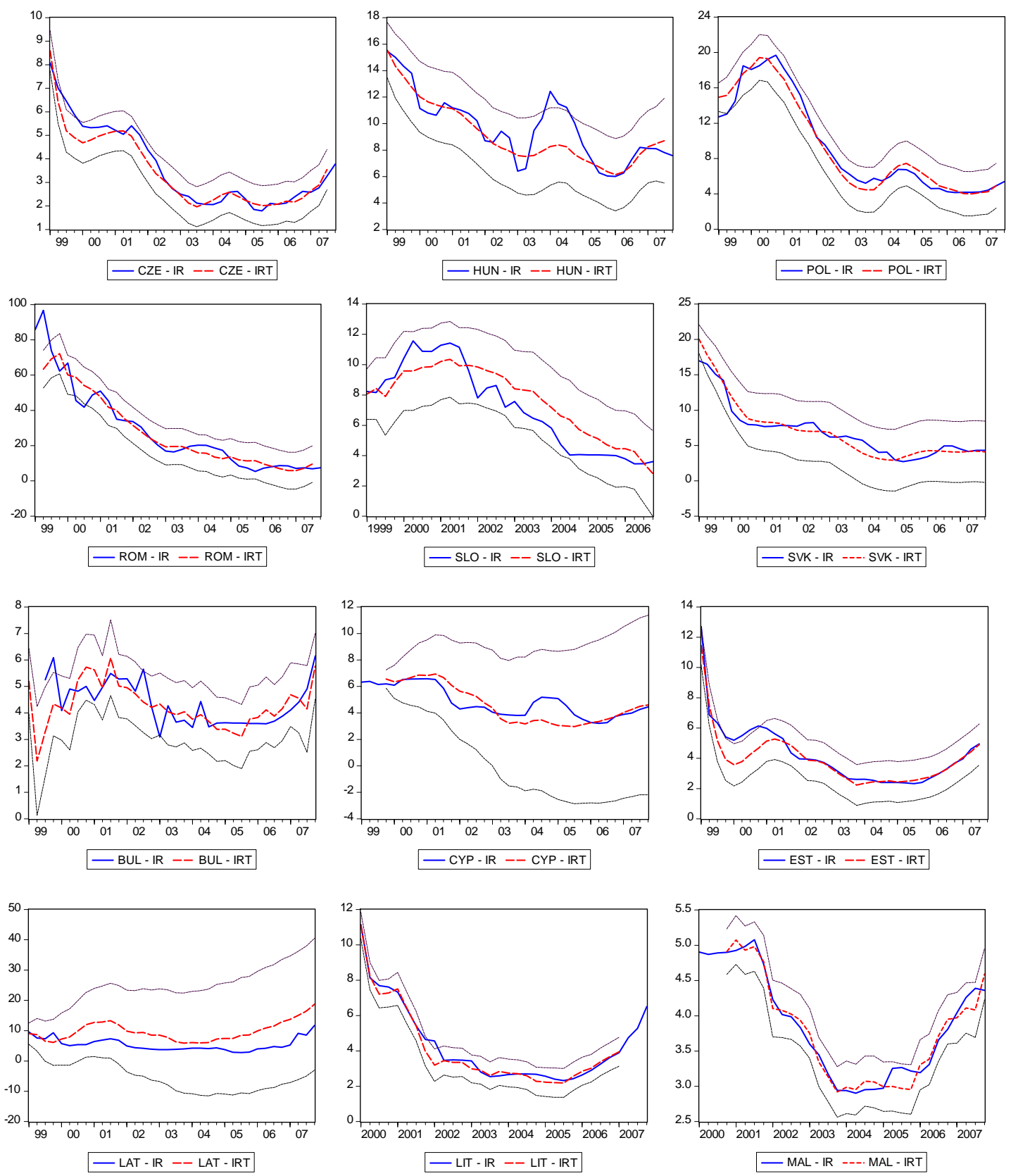

Figure 1.: The counterfactual experiment: the comparison of the target interest rate from the monetary policy rule with the highest explanatory power and the actual interest rate

We can see that monetary policy shocks are not practically present in countries pursuing DIT. The underlying reason could be that this monetary arrangement rests on confidence and any discretionary action can have problematic consequences. One notable exception is Hungary, where we identify a significant deviation of these two series between late 2002 and 2004. Therefore, it is interesting to examine this episode in more detail. The Hungarian forint became subject of a speculative attack at the end of 2002 and in early 2003 . The central bank 
was pursuing DIT but, at the same time, it pegged the forint exchange rate to the euro (with a relative wide fluctuation band of $\pm 15 \%$ ) in order to meet the requirements of the ERM II. The markets expected that, if any inconsistency appeared between these two policy objectives, the central bank would ensure its inflation target rather than the declared bands of the exchange rate fluctuation. Surprisingly, the Hungarian central bank decided for the second option (intervention against the Hungarian forint), which is related to a strong decrease of domestic interest rates in late 2002. This decrease was inconsistent with the interest rate setting in place. The result of such measure was a significant inflation increase and the central bank had to raise disproportionally the interest rates in the subsequent period. ${ }^{33}$

The departures of the actual interest rate from the target value are more common in some countries with fixed exchange rate, like Bulgaria or Cyprus. This seems to be rather related to lower overall fit of the estimated mode than to policy shocks. In the case of Latvia, we do not find any specification with a reasonable fit. However, as we pointed out above, if the interest rate adjusts endogenously to exchange rate interventions, the estimated interest rate rule cannot provide a good approximation of monetary policy.

\section{Empirical evidence on the inflation process in the NMS}

We have already discussed above that the sources of inflation dynamics can be quite complex in open economies. For this reason, we use an encompassing specification of an open economy PC (8). The OLS estimates of this model are shown in Table 3.

We can see that the inflation rates of the NMS are driven not only by their backward persistence (coefficient $\beta_{1}$ ) but they also hold significant forward-looking component (coefficient $\beta_{2}$ ). Studies critical with the NKPC (Bårdsen et al., 2004) argue that the effect of the forward-looking term vanishes once more lags of inflation are included. We include up to four lags of inflation to test this claim. While these turn mostly insignificant, the significance of the forward-looking term is not affected. Conversely, when the expected inflation is dropped, the backward-looking term does not increase substantially. In addition, we test the restricted version, where $\beta_{1}$ and $\beta_{2}$ sum to unity pursuant the original NKPC (Galí and Gertler, 1999). The overall fit of such model is always lower since they never sum to unity in

\footnotetext{
${ }^{33}$ This episode also confirms a problematic coexistence of inflation targeting regime, aimed at domestic inflation, and the exchange rate stabilization. As the fluctuation band was relatively wide, the Hungarian forint did not experience any disturbances in other moments.
} 
the unrestricted version. However, given that we do not work with genine inflation expectations, we do not interpret this finding in terms of inflation-output trade-off. ${ }^{34}$

Table 3.: OLS estimates of an open economy Phillips curve for each NMS

\begin{tabular}{|c|c|c|c|c|c|c|c|c|c|}
\hline Country & $\begin{array}{c}\alpha \\
\text { (const.) }\end{array}$ & $\begin{array}{c}\boldsymbol{\beta}_{1} \\
\left(\pi_{\mathrm{t}-1}\right) \\
\end{array}$ & $\begin{array}{c}\boldsymbol{\beta}_{2} \\
{ }^{\exp } \\
\left(\pi_{t+1}\right) \\
\end{array}$ & $\begin{array}{c}\boldsymbol{\delta} \\
\text { for } \\
\left(\pi_{t}\right)\end{array}$ & $\begin{array}{c}\gamma \\
\left(y_{t-1}\right) \\
\end{array}$ & $\begin{array}{c}\boldsymbol{\eta} \\
\left(\mathrm{s}_{\mathrm{t}-2}, \mathrm{~s}_{\mathrm{t}-1} *\right) \\
\end{array}$ & $\begin{array}{c}\mu \\
\left(i_{t-4}\right) \\
\end{array}$ & $\mathbf{R}^{2}$ & LB \\
\hline $\mathrm{CZE}$ & $-0.76(0.55)$ & $\mathbf{0 . 4 9}(0.04)$ & $\mathbf{0 . 4 0}(0.10)$ & $\mathbf{0 . 8 0}(0.27)$ & $\mathbf{0 . 3 1}(0.11)$ & $\mathbf{- 0 . 0 7}(0.02)$ & $\mathbf{0 . 1 2}(0.03)$ & 0.91 & $0.40^{+}$ \\
\hline HUN & $-0.33(0.90)$ & $\mathbf{0 . 6 0}(0.07)$ & $\mathbf{0 . 6 0}(0.07)$ & $0.64(0.38)$ & $-0.19(0.31)$ & $\mathbf{- 0 . 0 7}(0.03)$ & $\mathbf{0 . 1 4}(0.05)$ & 0.95 & 0.89 \\
\hline POL & $-0.59(0.68)$ & $0.66(0.10)$ & $\mathbf{0 . 5 7}(0.15)$ & $0.40(0.31)$ & $0.15(0.16)$ & $\mathbf{- 0 . 0 4} *(0.01)$ & $\mathbf{0 . 0 9}(0.04)$ & 0.96 & 0.79 \\
\hline ROM & $6.07(2.73)$ & $\mathbf{0 . 8 7}(0.14)$ & $\mathbf{0 . 4 5}(0.14)$ & $-2.41(1.37)$ & $-0.11(0.23)$ & $\mathbf{- 0 . 1 2} *(0.06)$ & $-0.02(0.10)$ & 0.98 & 0.10 \\
\hline SLO & $0.64(0.82)$ & $\mathbf{0 . 3 1}(0.11)$ & $\mathbf{0 . 4 5}(0.20)$ & $0.47(0.29)$ & $\mathbf{0 . 3 6}(0.18)$ & $\mathbf{- 0 . 4 3} *(0.10)$ & $0.11(0.07)$ & 0.96 & 0.67 \\
\hline SVK & $-0.50(1.76)$ & $0.64(0.05)$ & $\mathbf{0 . 5 6}(0.07)$ & $0.99(0.52)$ & $0.10(0.27)$ & $\mathbf{- 0 . 1 0}(0.03)$ & $-0.14(0.10)$ & 0.95 & $0.12^{+}$ \\
\hline BUL & $0.21(2.42)$ & $\mathbf{0 . 3 2}(0.08)$ & $\mathbf{0 . 5 5}(0.09)$ & $1.74(0.88)$ & $\mathbf{0 . 9 0}(0.28)$ & $0.02 *(0.05)$ & $0.09(0.30)$ & 0.76 & 0.22 \\
\hline CYP & $1.06(0.50)$ & $\mathbf{0 . 8 4}(0.05)$ & $\mathbf{0 . 5 9}(0.05)$ & $\mathbf{0 . 8 2}(0.29)$ & $0.08(0.05)$ & $\mathbf{- 0 . 1 6}^{*}(0.03)$ & $0.05(0.07)$ & 0.83 & $0.41^{+}$ \\
\hline EST (diff) & $0.02(0.08)$ & $0.44(0.11)$ & $\mathbf{0 . 3 9}(0.15)$ & $1.68(0.48)$ & $-0.08(0.10)$ & $0.04 *(0.07)$ & $0.02(0.06)$ & 0.56 & $0.23^{+}$ \\
\hline LAT (diff) & 0.12( & $0.37(0.21)$ & $\mathbf{0 . 3 6}(0.12)$ & $0.56(0.31)$ & $-0.29(0.18)$ & $-0.05 *(0.04)$ & $0.10(0.06)$ & 0.29 & 0.26 \\
\hline LIT & $-0.56(1.14)$ & $\mathbf{0 . 8 9}(0.07)$ & $\mathbf{0 . 4 6}(0.12)$ & $0.38(0.51)$ & $0.43(0.16)$ & $-0.03 *(0.06)$ & $0.09(0.05)$ & 0.89 & 0.60 \\
\hline MAL & $0.54(0.75)$ & $\mathbf{0 . 6 6}(0.08)$ & $\mathbf{0 . 6 2}(0.06)$ & $-0.21(0.33)$ & $-0.03(0.03)$ & $-0.01 *(0.02)$ & $\mathbf{0 . 1 7}(0.04)$ & 0.67 & $0.07^{+}$ \\
\hline
\end{tabular}

Notes: Standard errors in parenthesis. Coefficients statistically significant at $5 \%$ in bold. LB is p-value of Ljung-Box test for 1. order serial correlation $\left(^{+}\right.$indicated result after correction for AR(1) in residuals). diff - relation estimated in first differences, otherwise in levels. $\mathrm{s}_{\mathrm{t}}$ - yearly change of the nominal bilateral exchange rate w.r.t. the euro (countries in the 1. block) and yearly change of the real effective exchange rate (countries in the 2 . block).

The results reveal two basic properties of the inflation process: (a) the relative strength of backward versus forward-looking components that can be (with some degree of simplification) linked to the way in which prices are set. In particular, whether the economic subject are backward or forward-looking; (b) what is the exogenous variable that drives up inflation rate in the short-term. As for the first characteristics, the forward-looking component dominates in some countries (BUL, CYP, SLO), the backward-looking component is predominant in others (HUN, LIT, POL, ROM, SVK) or both components are of similar magnitude (CZE, EST, LAT, MAL). As for the identification of exogenous variable driving inflation, we find the following. A statistically significant effect of the inflation rate in the Euro area (coefficient $\delta$ ) is found for three countries (CYP, CZE, EST). A positive significant relation between inflation rate and the output gap (coefficient $\gamma$ ), in the spirit of a traditional $\mathrm{PC}$, is confirmed in four countries (CZE, SLO, BUL, LIT).$^{35}$ We detect a negative significant

\footnotetext{
${ }^{34}$ As a robustness check, we reestimate the equation by means of GMM (2 lags included as instrumental variables) finding reasonably similar estimates of most parameters. Only the coefficient of the foreign interest rate substantially increased its size. In some cases, the coefficient of expected inflation increased in detriment to the lagged inflation.

${ }^{35}$ It was reported elsewhere that the Phillips curve became flatter. There are several possible explanations like the effects of globalization, less nominal price adjustments (due to lower trend inflation) or an increase of central banks credibility.
} 
response to a (nominal) exchange rate appreciation (coefficient $\eta$ ) in all countries that maintained flexible exchange rate. Therefore, if the exchange rate depreciates (decrease of our variable) the domestic inflation rate increases as the imports become more costly. Yet, limited size of this coefficient shows that the ERPT is very incomplete. For the countries that maintain exchange rate pegs, we use the REER (against 12 main trading partners and deflated by CPI) instead but do not find a significant response to this variable (with an exemption of Cyprus). These findings are in line with empirical studies on the ERPT (Gagnon and Ihrig, 2004, Campa and Goldberg, 2005), which confirmed its significant decrease over the last decades as a result of a low inflation environment. Moreover, the ERPT falls away throught distribution channel and its impact on final consumer prices is limited. ${ }^{36}$ Finally, the response to (four-periods) lagged interest rate, which tracks the effect of monetary policy, is mostly insignificant. However, there are four countries where this coefficient is significant and displays positive rather than negative sign. This finding is counter-intuitive from the NewKeynesian point of view suggesting that an interest rate increase must lead to a decrease of the inflation rate. On the contrary, the Post-Keynesian cost-push theories of inflation argue that the interest rate is a cost in a productive process and its increase can have positive rather than negative effect on the inflation rate.

The previous analysis does not point to any distinctive pattern in inflation persistence (as represented by coefficient $\beta_{1}$ ) between countries with flexible exchange rate (and autonomous monetary policy) and countries using hard pegs. To get better picture on this issue we pool up the data for countries with flexible exchange rate (CZE, HUN, POL, ROM, SLO, SVK) and fixed exchange rate (BUL, CYP, EST, LAT, LIT, MAL) and apply the panel analysis. This setting is useful for overcoming the small sample bias but it also can bias the result if the homogeneity of slope coefficient is not justified. We use a fixed effect model with crosssection SUR weighting (LSDV, both in levels and first differences) and test the homogeneity of coefficients by Wald Test. The results are reported in Table 4.

\footnotetext{
${ }^{36}$ Orlowski (2005) used similar model as ours and confirmed that the ERPT effect was very limited in CZE, HUN and POL. Coricelli et al. (2006) found (by means of cointegration framework) a weaker ERPT in countries with DIT and flexible exchange rate (CZE, POL) and stronger where exchange rate was more rigid (HUN, SLO). Babetskaia-Kukharchuk (2007) reports for the Czech Republic that the CPI inflation rate response to the exchange rate shock occurred mostly within the first six months and its peak response was $8-12 \%$, which is very similar to the our coefficient - 7\%. Moreover, she confirms that the ERPT decreased in time, which may be related to the regime of inflation targeting. Bitans (2004) reports for the Czech Republic cumulative ERPT after first 6 months 9\%, for Hungary 20\% (us 7\%), Poland 31\% (us 4\%), Romania 23\% (us 12\%), Slovakia 21\% (us $10 \%$ ) and Slovenia 23\% (us 43\%). Unlike us, they also find the ERPT in rage of $20-30 \%$ for countries with exchange rate pegs to the euro. In any case, the VAR estimates of the ERPT are not fully comparable to our OLS estimates of the open economy PC.
} 
Table 4.: LSDV estimates with cross-section SUR weighting of the open economy Phillips curve for panels of 6 countries with flexible exchange rate and 6 countries with exchange rate pegs

\begin{tabular}{|c|c|c|c|c|c|c|c|c|c|}
\hline & $\begin{array}{c}\alpha \\
\text { (const.) }\end{array}$ & $\begin{array}{c}\boldsymbol{\beta}_{1} \\
\left(\pi_{\mathrm{t}-1}\right)\end{array}$ & $\begin{array}{c}\boldsymbol{\beta}_{2} \\
\exp \\
\left(\pi_{\mathrm{t}+1}\right)\end{array}$ & $\left.\begin{array}{c}\boldsymbol{\delta} \\
\left(\pi_{\mathrm{t}}{ }^{\text {for }}\right.\end{array}\right)$ & $\begin{array}{c}\gamma \\
\left(\mathrm{y}_{\mathrm{t}-1}\right)\end{array}$ & $\begin{array}{c}\boldsymbol{\eta} \\
\left(\mathrm{s}_{\mathrm{t}-1}\right)\end{array}$ & $\begin{array}{c}\boldsymbol{\mu} \\
\left(\mathrm{i}_{\mathrm{t}-4}\right)\end{array}$ & $\mathbf{R}^{2}$ & DB \\
\hline Flexible (levels) & & $\mathbf{0 . 7 9}(0.03)$ & $\mathbf{0 . 5 2}(0.04)$ & $0.33(0.18)$ & $-0.05(0.06)$ & $\mathbf{- 0 . 0 5}(0.01)$ & $\mathbf{0 . 0 7}(0.00)$ & 0.98 & 2.21 \\
\hline Wald Test & & 0.00 & 0.49 & 0.15 & 0.18 & 0.01 & 0.07 & & \\
\hline Fixed (levels) & & $\mathbf{0 . 6 8}(0.04)$ & $0.46(0.05)$ & $\mathbf{0 . 5 0}(0.21)$ & $-0.03(0.04)$ & $\mathbf{- 0 . 0 4}(0.01)$ & $0.03(0.03)$ & 0.73 & 2.10 \\
\hline Wald Test & & 0.00 & 0.75 & 0.08 & 0.01 & 0.12 & 0.46 & & \\
\hline
\end{tabular}

We conclude that coefficient homogeneity across all countries is often rejected. However, even if we for simplification assume homogeneity, there is still no indication about substantially different degree of inflation persistence between the two groups.

\section{Inflation and monetary policy}

The prevailing NK literature (e.g. Clarida et al. 1998, 2000) argues that an appropriate monetary policy rule is decisive for plausible inflation outcomes. ${ }^{37}$ We have shown that dejure monetary policy regimes in the NMS can be accompanied by empirical estimates of interest rate rules, which are very rough indications of de-facto monetary policy. In particular, the (expected) inflation rate seems to drive the interest rate dynamics in countries with flexible exchange rates and the rule of interest rate peg are presumably applied in countries pursuing stable exchange rate. However, we do not find any distinctive feature of inflation dynamics between these two groups of countries.

The inflation rates in the CEEC in overall decreased since the accomplishment of the economic transition. It is interesting to ask whether the monetary policy as tracked by our estimates of the policy rules makes a difference with regard to price stability. The inflation rate (see Table 5.) provides the most straightforward information on the price stability but it is not suitable for cross-country comparison given that the levels of inflation significantly differed at the beginning of the period of analysis.

\footnotetext{
${ }^{37}$ The debate on the sources of the Great Moderation is still open and many argue that it was rather a good luck (benign environment) than a good policy what drove the overall decrease in the inflation rates.
} 
Table 5.: Summary of some descriptive statistics HCPI inflation series (1999-2007)

\begin{tabular}{lcccc}
\hline Country & mean & st.dev. & max. & max. \\
\hline CZE & 2.31 & 1.50 & 5.03 & -0.60 \\
HUN & 6.81 & 2.59 & 10.93 & 2.40 \\
POL & 3.88 & 3.10 & 10.87 & 0.33 \\
ROM & 21.88 & 15.98 & 53.80 & 3.87 \\
SLO & 5.46 & 2.49 & 9.53 & 2.17 \\
SVK & 6.48 & 2.89 & 16.07 & 1.37 \\
\hline BUL & 6.19 & 3.05 & 11.83 & -0.83 \\
CYP & 2.56 & 1.30 & 5.63 & 0.33 \\
EST & 4.00 & 1.74 & 9.23 & 0.63 \\
LAT & 4.65 & 2.29 & 13.63 & 1.00 \\
LIT & 1.86 & 2.14 & 7.90 & 1.60 \\
MAL & 2.33 & 0.97 & 3.57 & -0.90 \\
\hline
\end{tabular}

Although there is some empirical evidence that inflation targeting drives down the inflation persistence (Kantonikas, 2004), our previous analysis has not confirmed this claim. However, besides the inflation rate there is another relevant statistics: the inflation volatility. If inflation is volatile, there is greater uncertainty about its future level, which has negative impact on the agents' inflation expectations. In particular, we aim at conditional volatility. Some studies for developed countries found that the inflation process is conditionally heteroskedastic (Dolado et al., 2004). Consequently, we allow for conditional heteroscedasticity in residuals of the open economy PC and reestimate the specification (8) by $\operatorname{GARCH}(1,1)$. The open economy PC estimates (mean equation) are only slightly different from the previous OLS estimates they are not reported here. ${ }^{38}$ The estimates of the variance equation (9) are resumed in Table 6.

Since all three parameters of the variance equation are significant only in few cases, GARCH $(1,1)$ may not be an appropriate model. However, the estimates give an insightful account of the conditional inflation variance. The constant term $\omega$, which is an estimate of the long-term inflation variance (unconditional inflation variance), and the GARCH term $v_{2}$ representing the impact of forecast variance from the last period, are significant in all countries with fixed exchange rate regimes. On the contrary, the coefficient of the long-term variance is not significant for countries with flexible exchange rates that pursued more independent monetary policy. The coefficient of the ARCH term $v_{1}$ is mostly negative or insignificant, confirming that the impact of new information from the last period is quite limited.

\footnotetext{
${ }^{38}$ As the standard errors decreased, the significance of several estimated coefficients increased.
} 
Table 6.: The estimates of the variance equation from the open economy Phillips curve estimated by $\operatorname{GARCH}(1,1)$

\begin{tabular}{llcc}
\hline Country & $\begin{array}{c}\omega \\
(\text { const. })\end{array}$ & $\begin{array}{c}v_{1} \\
\left(\xi_{\mathrm{t}-1}{ }^{2}\right)\end{array}$ & $\begin{array}{c}v_{2}{ }^{2} \\
\left(\sigma_{\mathrm{t}-1}\right)\end{array}$ \\
\hline CZE & $0.05(0.04)$ & $\mathbf{- 0 . 3 3}(0.14)$ & $\mathbf{0 . 9 9}(0.16)$ \\
HUN & $0.15(0.10)$ & $\mathbf{- 0 . 1 2}(0.05)$ & $0.61(0.36)$ \\
POL & $0.01(0.01)$ & $0.11(0.14)$ & $\mathbf{0 . 6 8}(0.15)$ \\
ROM & $0.14(0.07)$ & $0.20(0.13)$ & $\mathbf{0 . 4 8}(0.11)$ \\
SLO & $0.24(0.34)$ & $-0.20(0.16)$ & $0.02(1.70)$ \\
SVK & $0.00(0.00)$ & $-0.11(0.08)$ & $\mathbf{1 . 0 1}(0.25)$ \\
\hline BUL & $\mathbf{0 . 1 9}(0.09)$ & $-0.27(0.14)$ & $\mathbf{1 . 1 0}(0.11)$ \\
CYP & $\mathbf{0 . 1 1}(0.04)$ & $\mathbf{0 . 7 8}(0.24)$ & $\mathbf{- 0 . 5 7}(0.29)$ \\
EST (diff) & $\mathbf{0 . 1 5}(0.07)$ & $-0.19(0.12)$ & $\mathbf{0 . 6 9}(0.26)$ \\
LAT (diff) & $\mathbf{0 . 1 7}(0.05)$ & $\mathbf{- 0 . 3 2}(0.13)$ & $\mathbf{0 . 7 8}(0.20)$ \\
LIT & $\mathbf{0 . 0 6}(0.03)$ & $-0.20(0.11)$ & $\mathbf{0 . 8 8}(0.02)$ \\
MAL & $\mathbf{0 . 0 4}(0.00)$ & $-\mathbf{0 . 2 7}(0.06)$ & $\mathbf{0 . 9 2}(0.15)$ \\
\hline Notes: Standard errors in parenthesis. & Coefficients \\
statistically significant at $5 \%$ in bold.
\end{tabular}

This evidence suggests that the policy of interest rate pegs may be detrimental for domestic price stability. This may be so because the inflation process of any of these countries but Cyprus was significantly affected by the inflation developments of the Euro area (see Table 3 ). The exchange rate flexibility and autonomous monetary policy, in particular DIT, seems to be superior as the countries that applied this policy were able not only to decrease the level of inflation but also its (long-term) volatility. The series of conditional inflation variances are plotted together with HCPI inflation rates in Figure 2.

The figure clearly documents that the experience of the countries, which adopted explicit DIT (CZE, HUN, POL, ROM), was the most fortunate with regard to the objectives of the price stability. Poland and Romania achieved a significant disinflation during this period, employing a monetary policy rule consisting in a very strong response to expected inflation. The decrease of the inflation variance was also considerable in these countries. Romania adopted explicit inflation targeting only in 2005 but the policy rule estimates reveal that it pursued very strict anti-inflationist policy during the whole period of our analysis. This holds even thought the Romanian national bank officially sought to stabilize both the domestic prices and the exchange rate between 1999 and 2004. ${ }^{39}$ Given the existence of significant ERPT, responding to foreign exchange rate was not detrimental for domestic price stability. The response to expected inflation rate was weaker in Hungary and the Czech Republic. Consequently, the inflation rate decreased relatively less in Hungary than in Poland and

\footnotetext{
${ }^{39}$ We report for Romania the rule with domestic inflation only because it has the highest explanatory power. However, even when the exchange rate was included, we have still found very strong response to inflation.
} 
Romania alike the conditional inflation variance. The Czech Republic achieved good outcomes with more flexible version of the DIT the interest rate developments in the Euro area with rather persistent inflation volatility. Slovakia claimed to apply the DIT but we fail to detect any response to domestic inflation rate. According to our results, the Slovak short-term interest rate responded very strongly to the euro interest rate. A direct impact of the inflation in the Euro area on Slovak inflation is not evident (rejected by the OLS specification of PC but confirmed by GARCH) and the policy of shadowing the ECB decisions seems to have given mixed outcomes. Although the inflation rate generally decreased its evolution has been still turbulent in the analyzed post-transformational period. The inflation increased from $7 \%$ in early 1999 up to $15 \%$ one year later and similarly from 3\% up to $9 \%$ between 2002 and 2003. Slovenia experienced similar inflation jump from 5\% in 1999 up to $10 \%$ in $2000-2002$ but since then it has seen a steady disinflation process. Slovenia did not adopt the DIT and proclaimed to pursue monetary targeting regime but we have identified only negligible response to monetary growth while the response to domestic inflation rate was very strong.

None of the countries that aimed at exchange rate stabilization (CYP, EST, LAT, LIT, MAL) but one (BUL) experienced a significant inflation decrease since 1999. The common monetary policy, de facto imported by an interest rate peg, seems to have been too permissive to leash the inflationary tendencies embedded in the domestic economies. ${ }^{40}$ On the other hand, Lithuania experienced two-year period of deflation. Therefore, although the exchange rate pegs had certainly a positive impact on the initial disinflation, its subsequent maintenance proved problematic for countries whose economic fundaments differed from those of the anchoring economy.

\footnotetext{
${ }^{40}$ The situation of these countries resembles the developments of EMU members like Greece or Portugal, suffering positive inflation differential with respect to other EMU members.
} 

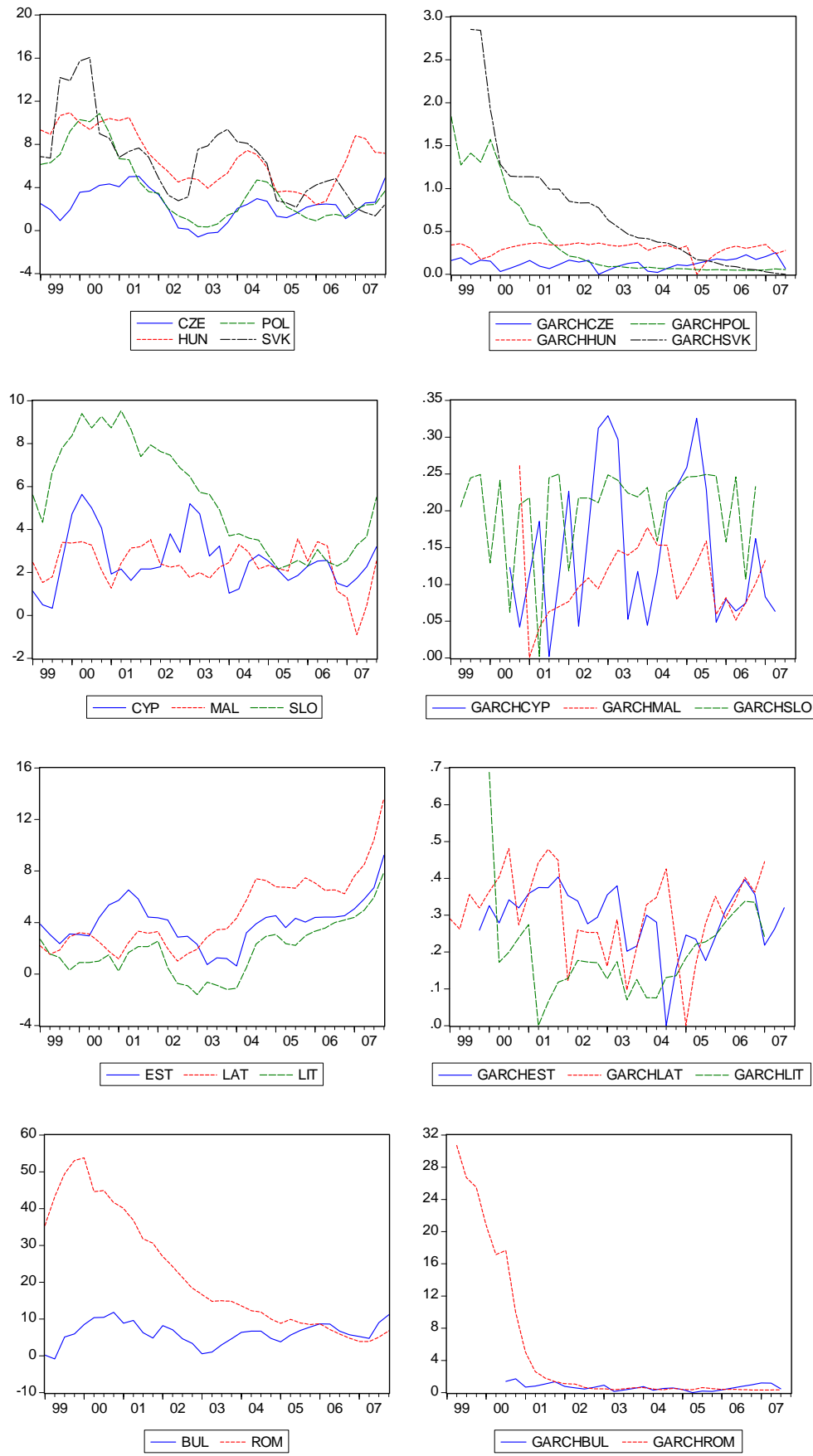

Figure 2.: HCPI-based inflation rate (left figure) and conditional inflation variance (right figure) (1. group - CZE, HUN, POL, SVK, 2. group - CYP, MAL, SLO, 3. group - EST, LAT, LIT, 4. group - BUL, ROM) 


\section{Conclusions}

This paper presents joint empirical evidence on monetary policy rules and on sources of inflation dynamics in small open economies, in particular in the 12 new EU members.

The estimated monetary policy rules point to a significant heterogeneity in interest rate setting, which is related to a variety of exchange rate arrangements in the NMS. We confirm a significant response of the short-term nominal interest rate to domestic inflation mostly for the inflation targeters. On the contrary, the policy rules of countries with hard exchange rate pegs seems to consist in mimicking the interest rate setting in the Euro area without major consideration of domestic macroeconomic developments. This evidence indicates that countries usually pursue either target for domestic inflation or for the exchange rate. However, it does not necessary imply that both targets cannot not be pursued simultaneously, especially if the domestic inflation has significant foreign component. The findings obtained for the countries with inflexible exchange rates can be loosely interpreted that a credible interest rate peg may constitute a means to fix the exchange rate. However, all our results are conditioned by rather strong assumption that the short-term interest rate is exogenously set by central bank while in reality it may endogenously adjust, e.g. to exchange rate interventions.

Our estimates of an open economy Philips curve point to the diversity of sources of the inflation process. In particular, the inflation rates are driven not only backward persistency but also hold a forward-looking component. The aggregate economic activity and foreign inflation development have direct impacts only in a few countries. In countries with flexible exchange rates, we identify that the exchange rate passes through to domestic consumer prices, although rather incompletely.

The nexus between the estimated monetary policy rules and the sources of the inflation process gives indications on the viability of the monetary policy setting for price stability. In particular, we find that the long-term component of the conditional inflation variance is higher in countries with exchange rate pegs. Consequently, inflation targeting seems to be a preferable strategy to exchange rate peg because it allows decreasing not only the inflation level but also its volatility.

There are several possible extensions of this research. We will point here only to three issues. First, although our objective was not to provide empirical evidence on the New Keynesian policy model (NKPM), we have estimated versions of two principal equations of this 
framework (monetary policy rule and the Phillips curve). Therefore, a natural extension could be their joint estimation, possibly also with the IS that completes the system, if any cross restrictions applies (Giordani, 2004). The estimation of complete NKPM has been usually carried our by means of VAR methods (Boivin and Giannoni, 2006). Such framework is useful for the identification of the effects of diverse shocks rather than for parameter estimation. Moreover, while the number of parameters that must be estimates in the system is very large the number of observations is rather limited. The preliminary results that we have obtained by employing both 3SLS and FIML estimators point to this problem. Cho and Moreno (2006) proposed a bootstrapping method to overcome the small-sample bias in this setting. Second, the GMM methodology commonly used for estimation of the monetary policy rule was recently questioned on ground of identification problems that arise in forwardlooking models (Mavroeidis, 2005). Therefore, a more detailed analysis should be carried out on this issue. Finally, we have relied on a potentially controversial variable - the output gap as a measure of the real economic activity and a determinant of inflation in the open economy PC. The NK literature suggested real marginal cost instead (Galí and Gertler, 1999). Unfortunately, this variable is not available with sufficiently long time spam for all the countries in our sample.

\section{References}

Ball, L., Sheridan, N. (2003): Does Inflation Targeting Matter? NBER Working Paper No. 9577.

Babetskaia-Kukharchuk, O. (2007): Transmission of Exchange Rate Shocks into Domestic Inflation: The Case of the Czech Republic. Czech National Bank Working Paper No. 12/2007.

Bårdsen, G., Janssen, E.S., Nymoen, R. (2004): Econometric Evaluation of the New Keynesian Phillips Curve. Oxford Bulletin of Economics and Statistics 66, 671-686.

Batini, N., Jackson, B., Nickell, S. (2005): An Open-economy New Keynesian Phillips Curve for the U.K. Journal of Monetary Economics 52, 1061-1071.

Benigno, G., Benigno, P., Ghironi, F. (2007): Interest Rate Rules for Fixed Exchange Rate Regimes. Journal of Economic Dynamics \& Control 31, 2196-2211.

Bitans, B. (2005): Pass-through of Exchange Rate to Domestic Prices in East European Countries and the Role of Economic Enviroment. Latvijas Banka Working Paper No. 2004/04.

Boivin, J., Giannoni, M.P. (2006): Has Monetary Policy Become More Effective. The Review of Economics and Statistics 88(3): 445-462.

Campa, J.M., Goldberg, L.S. (2005): Exchange Rate Pass-Through into Import Prices. The Review of Economics and Statistics 87(4), 679-690.

Cho, S., Moreno, A. (2006): A Small-Sample Study of the New-Keynesian Macro Model. Journal of Money, Credit and Banking 38(6), 1461-1481. 
Clarida, R., Galí, J., Gertler, M. (1998): Monetary Policy Rules in Practice: Some International Evidence. European Economic Review 42, 1033-1067.

Clarida, R., Galí, J., Gertler, M. (2000): Monetary Policy Rules and Macroeconomic Stability. The Quarterly Journal of Economics 115(1), 147-180.

Coricelli, F., Jazbec, B., Masten, I. (2006): Exchange Rate Pass-Through in EMU Acceding Countries: Empirical Analysis and Policy Implications. Journal of Banking \& Finance 30, 1375-1391.

Davidson, R., MacKinnon, J.G. (1993); Estimation and Inference in Econometrics. Oxford University Press: New York.

Dolado, J., María-Dolores, R., Ruge-Murcia, F.J. (2004): Nonlinear Monetary Policy Rules: Some New Evidence for the U.S. Studies in Nonlinear Dynamics \& Econometrics 8(3), Article 2.

Engle, R.F., Granger, C.W.J. (1987): Co-integration and Error Correction: Representation, Estimation, and Testing, Econometrica 55, 251-276.

Égert, B., Mihaljek, D. (2008): Determinants of House Prices in Central and Eastern Europe. Czech National Bank Working Paper No. 1/2008.

Filosa, R. (2001): Monetary Policy Rules in Some Mature Emerging Economies, BIS Papers No. 8, 39-68.

Franta, M., Saxa, B., Šmídková, K. (2007): Inflation Persistence: Euro area and the New Member States. European Central Bank Working Paper No. 810.

Frömmel, M., Schobert, F. (2006a): Exchange Rate Regimes in Central and East European countries: Deeds vs. words. Journal of Comparative Economics 34 (3), 467-483.

Frömmel, M., Schobert, F. (2006b): Monetary Policy Rules in Central and Eastern Europe. Discussion Paper No. 341, University of Hannover.

Fuhrer, J.C., Moore, G. (1995): Inflation Persistence. The Quarterly Journal of Economics 110 (1), 127-159.

Gagnon, J.E., Ihrig, J. (2004): Monetary Policy and Exchange Rate Pass-Through. International Journal of Finance and Economics 9, 315-338.

Galí, J., Gertler, M. (1999): Inflation dynamics: A structural econometric analysis. Journal of Monetary Economics 44, 195-222.

Galí, J., Gertler, M., Lopez-Salido, J.D. (2001): European inflation dynamics. European Economic Review 45, 1237-1270.

Giordani, P. (2004): Evaluating Small Keynesian Models of a Small Open Economy. Oxford Bulletin of Economics and Statistics 66, 713-733.

Johansen, S. (1991): Estimation and Hypothesis Testing of Cointegration Vectors in Gaussian Vector Autoregressive Models. Econometrica 59, 1551-1580.

Kontonicas, A. (2004): Inflation and Inflation Uncertainty in the United Kingdom, evidence from GARCH modeling. Economic Modelling 21, 525-543.

Linnemann, L., Schabert, A. (2006): Monetary Policy and the Taylor Principle in Open Economies. International Finance 9(3), 343-367.

María-Dolores, R. (2005): Monetary Policy Rules in Accession Countries to EU: IS Taylor rule a pattern? Economics Bulletin 5(5), 1-16.

Markiewicz, A. (2006): Choice of Exchange Rate Regime in Central and Eastern European Countries: An Empirical Analysis. Journal of Comparative Economics 34(3), 484-498. 
Mavroeidis, S. (2005): Identification Issues in Forward-Looking Models Estimated by GMM, with an Application to the Phillips Curve. Journal of Money, Credit, and Banking 37 (3), 421-448.

Mehra, Y.P. (2001): The Bond Rate and Estimated Monetary Policy Rules. Journal of Economics and Business, $53,345-358$.

Mohanty, M. S., Klau, M. (2007): Monetary Policy Rules in Emerging Market Economies: Issues and Evidence. In: R.J. Langhammer and L.Vinhas de Souza (eds.): Monetary Policy and Macroeconomic Stabilization in Latin America, Springer Berlin Heidelberg, 205-245.

Newey, W., West, K. (1994): Automatic Lag Selection in Covariance Matrix Estimation. Review of Economic Studies 61, 631-653.

Obstfeld, M., Rogoff, K. (1996): Foundations of International Macroeconomics. MIT Press, Cambridge, MA.

Orlowski, L.T. (2005): Monetary Convergence of the EU Accession Countries to the Eurozone: A Theoretical Framework and Policy Implications. Journal of Banking \& Finance 29, 203-225.

Rumler, F. (2007): Estimates of the Open Economy New Keynesian Phillips Curve for Euro Area Countries Open Economies Review 18, 427-451.

Svensson, L.E.O. (2000): Open-economy Inflation Targeting. Journal of International Economics 50, 155-183. Taylor, J.B. (1993): Discretion versus Policy Rules in Practice. Carnegie-Rochester Conference Series on Public Policy 39, 195-214.

Taylor, J.B. (2000): Low Inflation, Pass-Through, and the Pricing Power of Firms. European Economic Review 44, 1389-1408.

Taylor, J.B. (2001): Role of Exchange Rate in Monetary-Policy Rules. American Economic Review 91(2), 263267.

Terrones, M., Otrok, Ch. (2004): The Global House Price Boom. In: IMF: World Economic Outlook, Chapter 3, April. Washington: International Monetary Fund. 


\section{Appendix}

Table A.1. Previous studies on the monetary policy rules for NMS

\begin{tabular}{|c|c|c|c|c|c|c|}
\hline Reference & $\begin{array}{c}\text { Data } \\
\text { Method }\end{array}$ & Specification & & $\beta$ & $\gamma$ & $\rho$ \\
\hline $\begin{array}{l}\text { Angeloni, Flad } \\
\text { and Mongelli } \\
(2007)\end{array}$ & $\begin{array}{c}\text { CZE, HUN, POL } \\
\text { 99:01-04:12 } \\
\text { OLS } \\
\end{array}$ & $i_{t}=f\left(\pi_{t-1}, y_{t-1}, i_{t-1}, d u m m y\right)$ & $\begin{array}{l}\text { CZE } \\
\text { HUN } \\
\text { POL }\end{array}$ & $\begin{array}{c}0.85 \\
- \\
0.79 \\
\end{array}$ & $\begin{array}{c}- \\
- \\
0.79 \\
\end{array}$ & $\begin{array}{l}0.90 \\
0.95 \\
0.90 \\
\end{array}$ \\
\hline $\begin{array}{c}\text { Frömmer and } \\
\text { Schobert }(2006 b)\end{array}$ & $\begin{array}{c}\text { CZE, HUN, POL, } \\
\text { SLO, SVK, ROM } \\
\text { 94:01-05:02 } \\
\text { GMM }\end{array}$ & $i_{t}=f\left(\pi_{t+12}, y_{t}, i_{t-1}, \Delta r_{t}, \Delta r_{t-1}, \Delta m_{t}\right)$ & $\begin{array}{c}\text { CZE } \\
\text { HUN } \\
\text { POL } \\
\text { SLO } \\
\text { SVK } \\
\text { ROM }\end{array}$ & $\begin{array}{c}- \\
- \\
0.25 \\
0.11 \\
- \\
-\end{array}$ & $\begin{array}{c}0.04 \\
0.06 \\
- \\
- \\
- \\
- \\
\end{array}$ & $\begin{array}{l}0.99 \\
0.97 \\
0.97 \\
0.83 \\
0.82 \\
1.01 \\
\end{array}$ \\
\hline $\begin{array}{l}\text { María-Dolores } \\
\qquad(2005)\end{array}$ & $\begin{array}{c}\text { CZE,HUN,POL, SVK } \\
\text { 97/98-03:09 } \\
\text { OLS, GMM }\end{array}$ & $i_{t}=f\left(\pi_{t}, \pi_{t+k}, y_{t-1}, i_{t-1}\right)$ & $\begin{array}{l}\text { CZE } \\
\text { HUN } \\
\text { POL } \\
\text { SVK }\end{array}$ & $\begin{array}{l}0.59 \\
1.25 \\
1.20 \\
0.11 \\
\end{array}$ & $\begin{array}{c}0.24 \\
- \\
- \\
0.19 \\
\end{array}$ & $\begin{array}{l}0.83 \\
0.91 \\
0.92 \\
0.46 \\
\end{array}$ \\
\hline $\begin{array}{c}\text { Mohanty and } \\
\text { Klau (2007) }\end{array}$ & $\begin{array}{c}\text { CZE, HUN, POL } \\
\text { 95:01-02:12 } \\
\text { GMM }\end{array}$ & $i_{t}=f\left(\pi_{t}, \pi_{t}^{g a p}, y_{t}, i_{t-1}, \Delta r_{t}, \Delta r_{t}^{g a p}, \Delta r_{t-1}\right)$ & $\begin{array}{l}\text { CZE } \\
\text { HUN } \\
\text { POL }\end{array}$ & $\begin{array}{c}0.33 \\
- \\
0.16\end{array}$ & $\begin{array}{c}0.20 \\
- \\
0.66\end{array}$ & $\begin{array}{l}0.66 \\
0.75 \\
0.75\end{array}$ \\
\hline
\end{tabular}

Note: $i_{t}$-short-term interest rate (coefficient of its first lag $-\rho$ ), $\pi_{t}$-inflation rate (coefficient $\beta$ ), $y_{t}$ - output gap (coefficient $\gamma$ ), $r_{t}$ - exchange rate, $m_{t}$ - monetary aggregate, dummy - dummy variable for periods with different policy regimes. If more estimates were available, we report the one closest to our specification and estimation period.

Table A.2. Comparison of the AEG and Johansen tests of cointegration

\begin{tabular}{|c|c|c|c|c|}
\hline & \multicolumn{2}{|c|}{ Monetary policy rule } & \multicolumn{2}{|c|}{ Augmented Phillips curve } \\
\hline & AEG Test & Johansen Test & AEG Test & Johansen Test \\
\hline BUL & $\mathrm{i}_{\mathrm{t}}, \pi_{\mathrm{t}+1}, \mathrm{i}_{\mathrm{t}}^{\text {for }}$ & $i_{t}, i_{t}{ }^{\text {for }}$ & $\pi_{\mathrm{t}}, \pi_{\mathrm{t}-1}, \pi_{\mathrm{t}+1}{ }^{\exp }, \pi_{\mathrm{t}}^{\text {for }},\left(\mathrm{i}_{\mathrm{t}-4}\right)$ & $\pi_{\mathrm{t}}, \pi_{\mathrm{t}+1}{ }^{\exp }, \pi_{\mathrm{t}}^{\text {for }},\left(\mathrm{i}_{\mathrm{t}-4}\right)$ \\
\hline $\mathrm{CZE}$ & $\mathrm{i}_{\mathrm{t}}, \mathrm{i}_{\mathrm{t}-\mathrm{t}}, \pi_{\mathrm{t+1}}, \mathrm{i}_{\mathrm{t}}$ for & $i_{1}, \pi_{t+1}, i_{+}^{\text {for }}$ & exp for & $\pi$ exp for \\
\hline CYP & $\begin{array}{l}\mathrm{I}_{\mathrm{t}}, \mathrm{I}_{\mathrm{t}-1}, \pi_{\mathrm{t}+1}, \mathrm{I}_{\mathrm{t}} \\
\text { none }\end{array}$ & ${ }^{1}, \pi_{t+1}, I_{t}$ & $\mu_{t}, \mu_{t-1}, \mu_{t+1} e_{\exp }, \mu_{t},{ }_{t-4}$ & $\pi_{\mathrm{t}}, \pi_{\mathrm{t}+1} \exp _{\text {for }}, \mu_{\mathrm{t}-4}$ \\
\hline LIP & none for & none for & $\pi_{\mathrm{t}}, \pi_{\mathrm{t}-1}, \pi_{\mathrm{t}+1} \quad,\left(1_{\mathrm{t}-4}\right)$ & $\pi_{\mathrm{t}}, \pi_{\mathrm{t}+1} \quad, \pi_{\mathrm{t}} \quad, \mathrm{1}_{\mathrm{t}-4}$ \\
\hline EST & $i_{t}, \pi_{t-1}, i_{t} \quad$ for & $i_{t}, \pi_{t-1}, i_{t}$ for & none $\quad \exp \quad$ for & none $\exp$ for \\
\hline HUN & $\mathrm{i}_{\mathrm{t}}, \mathrm{i}_{\mathrm{t}-1}, \pi_{\mathrm{t}+1}, \mathrm{i}_{\mathrm{t}}$ & $\mathrm{i}_{\mathrm{t}}, \pi_{\mathrm{t}+1}, \mathrm{i}_{\mathrm{t}}$ & $\pi_{\mathrm{t}}, \pi_{\mathrm{t}-1}, \pi_{\mathrm{t}+1} \quad,\left(\pi_{\mathrm{t}}\right), \mathrm{i}_{\mathrm{t}-4}$ & $\pi_{\mathrm{t}}, \pi_{\mathrm{t}+1},\left(\pi_{\mathrm{t}}\right), \mathrm{i}_{\mathrm{t}-4}$ \\
\hline LAT & $\mathrm{i}_{\mathrm{t}}, \mathrm{i}_{\mathrm{t}-1}, \pi_{\mathrm{t}+1}, \mathrm{i}_{\mathrm{t}}$ & none & none & none \\
\hline LIT & $\mathrm{i}_{\mathrm{t}}, \mathrm{i}_{\mathrm{t}-1}, \pi_{\mathrm{t}-1}, \mathrm{i}_{\mathrm{t}}^{\text {for }}$ & $\mathrm{i}_{\mathrm{t}}, \pi_{\mathrm{t}-1}, \mathrm{i}_{\mathrm{t}}^{\mathrm{fc}}$ & $\pi_{\mathrm{t}}, \pi_{\mathrm{t}-1}, \pi_{\mathrm{t}+1} \stackrel{\exp }{\text { exp }},\left(\pi_{\mathrm{t}}^{\text {for }}\right), \mathrm{i}_{\mathrm{t}-4}$ & $\pi_{\mathrm{t}}, \pi_{\mathrm{t}+1} \stackrel{\exp }{\text { exp }},\left(\pi_{\mathrm{t}}^{\text {for }}\right), \mathrm{i}_{\mathrm{t}-4}$ \\
\hline MAL & $\mathrm{i}_{\mathrm{t}}, \mathrm{i}_{\mathrm{t}-1}$ & $\mathrm{i}_{\mathrm{t}}, \mathrm{i}_{\mathrm{t}}{ }^{\mathrm{t}}$ & $\pi_{\mathrm{t}}, \pi_{\mathrm{t}-1}, \pi_{\mathrm{t}+1}, \mathrm{i}_{\mathrm{t}-4}, \mathrm{~s}_{\mathrm{t}-1}$ & $\pi_{\mathrm{t}}, \pi_{\mathrm{t}+1},\left(\pi_{\mathrm{t}}\right), \mathrm{i}_{\mathrm{t}-4},\left(\mathrm{~s}_{\mathrm{t}-1}\right)$ \\
\hline POL & $\mathrm{i}_{\mathrm{t}}, \mathrm{i}_{\mathrm{t}-1}, \pi_{\mathrm{t}+1}$ & $\mathrm{i}_{\mathrm{t}}, \pi_{\mathrm{t}+1}$ & $\pi_{t}, \pi_{t-1}, \pi_{t+1},\left(\pi_{t}\right), i_{t-4}$ & $\pi_{\mathrm{t}}, \pi_{\mathrm{t}+1},\left(\pi_{\mathrm{t}}\right), \mathrm{i}_{\mathrm{t}-4}$ \\
\hline ROM & $\mathrm{i}_{\mathrm{t}}, \pi_{\mathrm{t}+1}$ & $\mathrm{i}_{\mathrm{t}}, \pi_{\mathrm{t}+1}$ & $\pi_{\mathrm{t}},\left(\pi_{\mathrm{t}-1}\right), \pi_{\mathrm{t}+1},\left(\pi_{\mathrm{t}}\right), \mathrm{i}_{\mathrm{t}-4}$ & $\pi_{\mathrm{t}}, \pi_{\mathrm{t}+1},\left(\pi_{\mathrm{t}}\right), \mathrm{i}_{\mathrm{t}-4}$ \\
\hline SLO & $\mathrm{i}_{\mathrm{t}}, \pi_{\mathrm{t}+1}$ & $\mathrm{i}_{\mathrm{t}}, \pi_{\mathrm{t}+1}$ & $\pi_{\mathrm{t}}, \pi_{\mathrm{t}-1}, \pi_{\mathrm{t}+1}^{\exp },\left(\pi_{\mathrm{t}}^{\text {for }}\right), \mathrm{i}_{\mathrm{t}-4}$ & $\pi_{\mathrm{t}}, \pi_{\mathrm{t}+1}^{\exp },\left(\pi_{\mathrm{t}}^{\text {for }}\right), \mathrm{i}_{\mathrm{t}-4}$ \\
\hline SVK & $\mathrm{i}_{\mathrm{t}}, \pi_{\mathrm{t}-1}, \mathrm{i}_{\mathrm{t}}$ & $\mathrm{i}_{\mathrm{t}}, \pi_{\mathrm{t}-1}, \mathrm{i}_{\mathrm{t}}$ & $\pi_{\mathrm{t}},\left(\pi_{\mathrm{t}-1}\right), \pi_{\mathrm{t}+1},\left(\pi_{\mathrm{t}}\right), \mathrm{i}_{\mathrm{t}-4}$ & $\pi_{\mathrm{t}}, \pi_{\mathrm{t}+1},\left(\pi_{\mathrm{t}}\right), \mathrm{i}_{\mathrm{t}-4}$ \\
\hline
\end{tabular}


Table A.3. Granger causality test between the short-term interest rate of each country (STIR...) and the euro interest rate (STIREUR) - left panel and between the short-term interest rate (STIR...) and the corresponding long-term interest rate (LTIR...) - right panel

\begin{tabular}{|c|c|c|c|}
\hline Null Hypothesis & F-Stat. & P-value & Lags \\
\hline STIREUR $\neq>$ STIRBUL & 17.24 & 0.00 & 1 \\
\hline STIRBUL $\neq>$ STIREUR & 2.76 & 0.11 & \\
\hline STIREUR $\neq>$ STIRCYP & 0.33 & 0.57 & 1 \\
\hline STIRCYP $\neq>$ STIREUR & 1.22 & 0.27 & \\
\hline STIREUR $\neq>$ STIRCZE & 15.73 & 0.00 & 1 \\
\hline STIRCZE $\neq>$ STIREUR & 1.41 & 0.24 & \\
\hline STIREUR $\neq>$ STIREST & 26.43 & $\mathbf{0 . 0 0}$ & 1 \\
\hline STIREST $\neq>$ STIREUR & 2.39 & 0.13 & \\
\hline STIREUR $\neq>$ STIRHUN & 0.05 & 0.82 & 1 \\
\hline STIRHUN $\neq>$ STIREUR & 0.31 & 0.26 & \\
\hline STIREUR $\neq>$ STIRLAT & 4.59 & 0.04 & 1 \\
\hline STIRLAT $\neq>$ STIREUR & 0.32 & $\mathbf{0 . 5 7}$ & \\
\hline STIREUR $\neq>$ STIRLIT & 69.84 & $\mathbf{0 . 0 0}$ & 1 \\
\hline STIRLIT $\neq>$ STIREUR & 1.13 & $\mathbf{0 . 3 0}$ & \\
\hline STIREUR $\neq>$ STIRMAL & 13.80 & 0.01 & 1 \\
\hline STIRMAL $\neq>$ STIREUR & 0.22 & 0.64 & \\
\hline STIREUR $\neq>$ STIRPOL & 2.11 & 0.16 & 1 \\
\hline STIRPOL $\neq>$ STIREUR & 0.24 & 0.63 & \\
\hline STIREUR $\neq>$ STIRROM & 0.50 & 0.49 & 1 \\
\hline STIRROM $\neq>$ STIREUR & 0.31 & 0.58 & \\
\hline STIREUR $\neq>$ STIRSLO & 0.45 & 0.51 & 1 \\
\hline STIRSLO $\neq>$ STIREUR & 0.34 & 0.56 & \\
\hline STIREUR $\neq>$ STIRSVK & 4.25 & 0.02 & 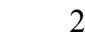 \\
\hline STIRSVK $\nRightarrow>$ STIREUR & 0.72 & 0.49 & \\
\hline
\end{tabular}

\begin{tabular}{lrrrr}
\hline Null Hypothesis & \multicolumn{3}{c}{ F-Stat. P-value Lags } \\
\hline LTIRBUL $\neq>$ STIRBUL & 0.56 & 0.47 & 1 \\
STIRBUL $\neq>$ LTIRBUL & 1.06 & 0.31 & \\
\hline LTIRCYP $\neq>$ STIRCYP & 1.86 & 0.18 & 1 \\
STIRCYP $\neq>$ LTIRCYP & 20.19 & 0.00 & \\
\hline LTIRCZE $\neq>$ STIRCZE & 5.19 & $\mathbf{0 . 0 3}$ & 1 \\
STIRCZE $\neq>$ LTIRCZE & 0.02 & $\mathbf{0 . 9 0}$ & \\
\hline LTIREST $\neq>$ STIREST & 18.88 & $\mathbf{0 . 0 0}$ & 1 \\
STIREST $\neq>$ LTIREST & 0.73 & $\mathbf{0 . 4 0}$ & \\
\hline LTIRHUN $\neq>$ STIRHUN & 0.25 & 0.62 & 1 \\
STIRHUN $\neq>$ LTIRHUN & 0.46 & 0.24 & \\
\hline LTIRLAT $\neq>$ STIRLAT & 1.77 & 0.20 & 1 \\
STIRLAT $\neq>$ LTIRLAT & 1.60 & 0.22 & \\
\hline LTIRLIT $\neq>$ STIRLIT & 16.31 & 0.00 & 1 \\
STIRLIT $\neq>$ LTIRLIT & 4.04 & 0.06 & \\
\hline LTIRMAL $\neq>$ STIRMAL & 19.55 & 0.00 & 1 \\
STIRMAL $\neq>$ LTIRMAL & 19.16 & 0.00 & \\
\hline LTIRPOL $\neq>$ STIRPOL & 1.34 & 0.26 & 1 \\
STIRPOL $\neq>$ LTIRPOL & 8.27 & 0.00 & \\
\hline LTIRROM $\neq>$ STIRROM & & & \\
STIRROM $\neq>$ LTIRROM & & & \\
\hline LTIRSLO $\neq>$ STIRSLO & 5.22 & $\mathbf{0 . 0 4}$ & 1 \\
STIRSLO $\neq>$ LTIRSLO & 0.26 & $\mathbf{0 . 6 2}$ & \\
\hline LTIRSVK $\neq>$ STIRSVK & 1.94 & 0.18 & 1 \\
STIRSVK $\neq>$ LTIRSVK & 0.26 & 0.62 & \\
\hline
\end{tabular}

Notes: The presence of the Granger causality of euro short-term interest (domestic long-term interest rate) on the domestic short-term interest rate at $5 \%$ significance level marked by bold. 
Tables A.4. Detailed GMM estimates of monetary policy rules of the NMS

\begin{tabular}{|c|c|c|c|c|c|c|c|c|c|}
\hline $\begin{array}{l}\text { Bulgaria } \\
\text { 2000:1-2007:4 }\end{array}$ & $\begin{array}{c}\rho \\
\left(\mathrm{i}_{\mathrm{t}-1}\right)\end{array}$ & $\begin{array}{c}\alpha \\
\text { (const.) }\end{array}$ & $\begin{array}{c}\beta \\
\left(\pi_{\mathrm{t}-1}, \pi_{\mathrm{t}+1} *\right)\end{array}$ & $\begin{array}{c}\gamma \\
\left(, y_{t-1}\right)\end{array}$ & $\left(\mathrm{i}_{\mathrm{t}}{ }^{\text {for }}\right)$ & $\begin{array}{c}\zeta \\
\left(\mathrm{x}_{\mathrm{t}-1}, \mathrm{x}_{\mathrm{t}} *\right)\end{array}$ & $\mathrm{R}^{2}$ & LB & J-stat. \\
\hline $\mathrm{BL}$ & & $3.31(0.79)$ & $0.20(0.13)$ & $0.25(0.49)$ & & & 0.11 & $0.41 *$ & 0.40 \\
\hline FL & & $5.26(0.74)$ & $-0.17 *(0.09)$ & $1.16(0.34)$ & & & -0.85 & $0.47 *$ & 0.95 \\
\hline $\mathrm{BL}+\mathrm{SMT}$ & $1.08(0.24)$ & $0.40(0.66)$ & $-0.10(0.10)$ & $0.73(0.39)$ & & & -0.03 & $0.13 *$ & 0.71 \\
\hline $\mathrm{BL}+\mathrm{SMT}+\mathrm{FIR}$ & $0.63(0.35)$ & $0.30(0.75)$ & $-0.08(0.07)$ & $0.08(0.37)$ & $0.64(0.35)$ & & 0.42 & 0.93 & 0.37 \\
\hline BL + FIR & & $1.46(0.43)$ & $0.04(0.08)$ & $\mathbf{- 0 . 6 4}(0.20)$ & $0.79(0.16)$ & & 0.44 & 0.58 & 0.73 \\
\hline $\mathrm{BL}+\mathrm{FIR}+\mathrm{REER}$ & & $2.25(0.23)$ & $0.00(0.07)$ & $-0.02(0.16)$ & $\mathbf{0 . 6 4}(0.16)$ & $\mathbf{0 . 0 5}(0.01)$ & 0.51 & 0.05 & 0.64 \\
\hline $\mathrm{BL}+\mathrm{FIR}+\mathrm{SHI}$ & & $1.44(0.43)$ & $0.04(0.03)$ & $-0.20(0.30)$ & $0.76(0.11)$ & $0.00 *(0.00)$ & 0.19 & 0.67 & 0.62 \\
\hline $\mathrm{BL}+\mathrm{FIR}+\mathrm{MA}$ & & $1.86(0.51)$ & $0.00(0.10)$ & $-0.38(0.23)$ & $\mathbf{0 . 5 0}(0.09)$ & $0.03 *(0.04)$ & 0.33 & 0.17 & 0.73 \\
\hline BL + FIR + LTIR & - & - & & & & & & & \\
\hline
\end{tabular}

Notes: Standard errors in parenthesis. Coefficients statistically significant at 5\% in bold. LB is p-value of Ljung-Box test for 1 . order serial correlation. * indicated result after AR(1) correction, after AR(1), AR(2) correction.. J-stat is p-value of Sargan overidentification test. Best rule is in bold. Additional variables $x$ : NER - nominal exchange rate EUR/USD, REER - real effective exchange rate, $\mathrm{SHI}$ - asset prices, MA - monetary growth, LTIR - long-term interest rate.

\begin{tabular}{|c|c|c|c|c|c|c|c|c|c|}
\hline $\begin{array}{l}\text { Cyprus } \\
\text { 2000:2-2007:4 } \\
\end{array}$ & $\begin{array}{c}\rho \\
\left(\mathrm{i}_{\mathrm{t}-1}\right)\end{array}$ & $\begin{array}{c}\alpha \\
\text { (const.) }\end{array}$ & $\begin{array}{c}\beta \\
\left(\pi_{\mathrm{t}-1}, \pi_{\mathrm{t}+1} *\right) \\
\end{array}$ & $\begin{array}{c}\gamma \\
\left(y_{t-1}\right)\end{array}$ & $\left(i_{t}{ }_{\text {for }}^{\delta}\right)$ & $\begin{array}{c}\zeta \\
\left(\mathrm{x}_{\mathrm{t}-1}, \mathrm{x}_{\mathrm{t}}^{*}\right)\end{array}$ & $\mathrm{R}^{2}$ & LB & J-stat. \\
\hline BL & & $5.53(0.84)$ & $-0.34(0.29)$ & $0.99(0$. & & & & $3 *$ & * 0.46 \\
\hline $\mathrm{BL}+\mathrm{SMT}$ & $.85(0.16)$ & $0.37(0.94)$ & $0.18(0.20)$ & $-0.29(0.73)$ & & & 0 & $0 *$ & * 0.49 \\
\hline $\mathrm{BL}+\mathrm{SMT}+\mathrm{FIR}$ & $\mathbf{0 . 4 5}(0.21)$ & $2.38(0.77)$ & $-0.09(0.07)$ & $0.16(0.15)$ & $0.11(0.19)$ & & 0.90 & $.18^{*}$ & * 0.63 \\
\hline BL + SMT + FIR (diff.) & $\mathbf{0 . 2 2}(0.08)$ & $-0.07(0.08)$ & $\mathbf{- 0 . 1 4}(0.05)$ & $0.10(0.12)$ & $0.69(0.19)$ & & 0.35 & $0.57^{*}$ & * 0.69 \\
\hline $\mathrm{BL}+\mathrm{FIR}$ & & $3.45(1.19)$ & $-0.05(0.07)$ & $0.16(0.21)$ & $0.39(0.33)$ & & 0.90 & $0.00^{*}$ & * 0.79 \\
\hline $\mathrm{BL}+\mathrm{SMT}+\mathrm{REER}$ & $\mathbf{0 . 7 7}(0.24)$ & $0.86(1.80)$ & $0.11(0.13)$ & $-0.29(0.24)$ & & $0.24 \quad(0.27)$ & 0.86 & $0.21 *$ & * 0.24 \\
\hline $\mathrm{BL}+\mathrm{SMT}+\mathrm{SHI}$ & $\mathbf{0 . 4 0}(0.13)$ & $2.81(0.72)$ & $0.04(0.04)$ & $0.39(0.28)$ & & $0.00 *(0.00)$ & 0.81 & $0.74 *$ & * 0.55 \\
\hline $\mathrm{BL}+\mathrm{SMT}+\mathrm{MA}$ & $1.27(0.25)$ & $-2.28(1.24)$ & $0.15(0.06)$ & $\mathbf{- 0 . 5 1}(0.16)$ & & $0.04 *(0.02)$ & 0.78 & $0.13 *$ & * 0.57 \\
\hline $\mathrm{BL}+\mathrm{SMT}+\mathrm{LTIR}$ & $0.52(0.81)$ & $0.45(0.71)$ & $-0.04(0.11)$ & $0.17(0.28)$ & & $0.34 \quad(0.54)$ & 0.8 & $0.02 *$ & * 0.49 \\
\hline
\end{tabular}

Notes: See for Bulgaria. diff. - equation estimated in first differences

\begin{tabular}{|c|c|c|c|c|c|c|c|c|}
\hline $\begin{array}{l}\text { Czech republic } \\
\text { 1999:1-2007:3 }\end{array}$ & $\begin{array}{c}\rho \\
\left(\mathrm{i}_{\mathrm{t}-1}\right)\end{array}$ & $\begin{array}{c}\alpha \\
\text { (const.) }\end{array}$ & $\begin{array}{c}\beta \\
\left(\pi_{\mathrm{t}-1}, \pi_{\mathrm{t}+1} *\right)\end{array}$ & $\begin{array}{c}\gamma \\
\left(y_{t-1}\right)\end{array}$ & $\left(\mathrm{i}_{\mathrm{t}}^{\delta}\right)$ & $\begin{array}{c}\zeta \\
\left(\mathrm{x}_{\mathrm{t}-1}, \mathrm{x}_{\mathrm{t}}^{*}\right)\end{array}$ & $\mathrm{R}^{2} \mathrm{LB}$ & J-st \\
\hline FL & & $1.84(0.49)$ & $0.22 *(0.11)$ & $0.38(0.29)$ & & & 0.950 .44 & 0.24 \\
\hline $\mathrm{FL}+\mathrm{s}$ & $.70(0.03)$ & $\mathbf{0 . 4 5}(0.22)$ & $\mathbf{0 . 1 9} *(0.06)$ & $0.09 \quad(0$. & & & 0.940 .13 & 0.71 \\
\hline FL + SMT + FIR & $0.63(0.04)$ & $\mathbf{- 0 . 6 2}(0.19)$ & 0.16* $(0.03)$ & $\mathbf{- 0 . 2 3}(0.08)$ & $\mathbf{0 . 4 1}(0.10)$ & & 0.970 .24 & 0.88 \\
\hline FL + SMT + FIR & & $-0.54 \quad(0.30)$ & $\mathbf{0 . 1 8} *(0.07)$ & $-0.25(0.13)$ & $0.48(0.12)$ & & & 0.83 \\
\hline $\mathrm{FL}+\mathrm{FIR}$ & & $0.53(1.76)$ & $\mathbf{0 . 2 2} *(0.07)$ & $0.00 \quad(0.55)$ & $0.42(0.58)$ & & 0.950 .42 & 0.38 \\
\hline $\mathrm{FL}+$ & & $-0.43(0.25)$ & 0.11* $(0.04)$ & $-0.10 \quad(0.13)$ & 0.40 & & 0.970 .87 & 0.47 \\
\hline $\mathrm{FL}+\mathrm{S}$ & & $\mathbf{- 0 . 6 1}(0.22)$ & $\mathbf{0 . 1 7} *(0.0$ & $\mathbf{- 0 . 2 2}(0$. & $\mathbf{0 . 3 8}(0.09)$ & 0.00 & 0.970 .67 & 0.63 \\
\hline $\mathrm{FL}+\mathrm{SMT}+\mathrm{FIR}$ & $\mathbf{0 . 6 4}(0.04)$ & $\mathbf{- 0 . 6 5}(0.18)$ & $\mathbf{0 . 1 4} *(0.05$ & $\mathbf{- 0 . 2 1}(0.09)$ & $0.44(0.1$ & $0.00 *(0.00)$ & 0.960 .15 & 0.90 \\
\hline $\mathrm{FL}+\mathrm{SMT}+\mathrm{FIR}+$ & $\mathbf{0 . 6 4}(0.02)$ & $\mathbf{- 1 . 0 7}(0.18)$ & $\mathbf{0 . 1 5} *(0.03)$ & $\mathbf{- 0 . 2 5}(0.06)$ & $0.48(0.07)$ & $\mathbf{0 . 0 4} *(0.01)$ & 0.970 .02 & 0.45 \\
\hline $\mathrm{FL}+\mathrm{SMT}+\mathrm{FIR}+\mathrm{LTIR}$ & $\mathbf{0 . 4 8}(0.16)$ & 0.36 & $-0.06^{*}(0.10)$ & $\mathbf{0 . 4 4}(0.20)$ & $\mathbf{- 0 . 3 0}(0.18)$ & $-0.47(0.23)$ & 0.940 .14 & 0.76 \\
\hline
\end{tabular}

Notes: See for Bulgaria. infl. gap - inflation gap (inflation deviation from HP trend value) used instead of inflation rate 


\begin{tabular}{|c|c|c|c|c|c|c|c|c|c|c|c|c|}
\hline $\begin{array}{l}\text { Estonia } \\
\text { 1999:1-2007:3 } \\
\end{array}$ & $\begin{array}{c}\rho \\
\left(\mathrm{i}_{\mathrm{t}-1}\right)\end{array}$ & (cor & $\begin{array}{l}\alpha \\
\text { nst.) } \\
\end{array}$ & $\left(\pi_{\mathrm{t}-1,}\right.$ & $\left.\pi_{\mathrm{t}+1} *\right)$ & & & $\left(\begin{array}{c}\delta \\
\left(\mathrm{i}_{\mathrm{t}-1}\right)\end{array}\right.$ & $\begin{array}{c}\zeta \\
\left(\mathrm{x}_{\mathrm{t}-1}, \mathrm{x}_{\mathrm{t}}^{*}\right)\end{array}$ & $\mathrm{R}^{2}$ & $\mathrm{LB}$ & J-stat. \\
\hline BL & & 4.43 & $(1.80)$ & -0.22 & $(0.44)$ & 0.46 & $(0.21)$ & & & 0.83 & $0.50 *$ & 0.87 \\
\hline FL & & 1.87 & $(0.81)$ & $0.33 *$ & $(0.17)$ & 0.16 & $(0.15)$ & & & 0.90 & $0.37 *$ & 0.45 \\
\hline $\mathrm{FL}+\mathrm{SMT}$ & $\mathbf{0 . 8 2}(0.03)$ & 0.25 & $(0.09)$ & $0.08 *$ & $(0.02)$ & 0.10 & $(0.04)$ & & & 0.75 & $0.10^{*}$ & 0.36 \\
\hline FL + SMT + FIR (t-1) & $\mathbf{0 . 5 4}(0.02)$ & 0.04 & $(0.13)$ & $0.09 *$ & $(0.03)$ & 0.06 & $(0.05)$ & $\mathbf{0 . 3 9}(0.08)$ & & 0.92 & 0.76 & 0.74 \\
\hline $\mathrm{FL}+\mathrm{FIR}$ & & -0.68 & $(0.26)$ & $0.05^{*}$ & $(0.06)$ & -0.13 & $(0.05)$ & & & 0.19 & 0.00 & 0.68 \\
\hline $\mathrm{FL}+\mathrm{SMT}+\mathrm{FIR}+\mathrm{REER}$ & $\mathbf{0 . 5 4}(0.02)$ & 0.07 & $(0.14)$ & $0.06^{*}$ & $(0.05)$ & 0.06 & $(0.04)$ & $0.40(0.07)$ & $0.03(0.04)$ & 0.92 & 0.87 & 0.83 \\
\hline $\mathrm{FL}+\mathrm{SMT}+\mathrm{FIR}+\mathrm{SHI}$ & $\mathbf{0 . 5 6}(0.03)$ & -0.28 & $(0.31)$ & $0.10^{*}$ & $(0.03)$ & 0.04 & $(0.06)$ & $\mathbf{0 . 4 3}(0.07)$ & $0.00 *(0.00)$ & 0.92 & 0.62 & 0.82 \\
\hline $\mathrm{FL}+\mathrm{SMT}+\mathrm{FIR}+\mathrm{MA}$ & & 0.12 & $(0.33)$ & $0.10 *$ & $(0.17)$ & 0.07 & $(0.07)$ & $\mathbf{0 . 3 8}(0.12)$ & $0.00 *(0.03)$ & 0.90 & 0.90 & 0.69 \\
\hline $\mathrm{FL}+\mathrm{SMT}+\mathrm{FIR}+\mathrm{LTIR}$ & $\mathbf{0 . 6 0}(0.06)$ & 0.04 & $(0.36)$ & $0.13 *$ & $(0.05)$ & 0.10 & $(0.07)$ & $-0.02(0.18)$ & $\mathbf{0 . 1 7}(0.07)$ & 0.91 & 0.24 & 0.62 \\
\hline
\end{tabular}

Notes: See for Bulgaria

\begin{tabular}{|c|c|c|c|c|c|c|c|c|}
\hline $\begin{array}{l}\text { Hungary } \\
\text { 1999:1-2007:3 } \\
\end{array}$ & $\begin{array}{c}\rho \\
\left(\mathrm{i}_{\mathrm{t}-1}\right) \\
\end{array}$ & $\begin{array}{c}\alpha \\
\text { (const.) }\end{array}$ & $\begin{array}{c}\beta \\
\left(\pi_{\mathrm{t}-1}, \pi_{\mathrm{t}+1} *\right) \\
\end{array}$ & $\begin{array}{c}\gamma \\
\left(y_{t-1}\right)\end{array}$ & $\begin{array}{c}\delta \\
\left(i_{t}^{\text {for }}\right.\end{array}$ & $\begin{array}{c}\zeta \\
\left(\mathrm{x}_{\mathrm{t}-1}, \mathrm{x}_{\mathrm{t}}^{*}\right) \\
\end{array}$ & LB & J-stat. \\
\hline $\mathrm{BL}$ & & $6.07 \quad(1.87)$ & $0.13(0.16)$ & $-0.06(0.80)$ & & & $0.830 .13^{*}$ & 0.73 \\
\hline FL & & 3.42 (1.12) & $\mathbf{0 . 7 5}^{*}(0.12)$ & $-0.88(0.34)$ & & & $0.840 .18^{*}$ & 0.33 \\
\hline $\mathbf{F L}+\mathbf{S M T}$ & $\mathbf{0 . 7 1}(0.11)$ & $1.18(0.92)$ & $\mathbf{0 . 2 0} *(0.08)$ & $-0.12(0.58)$ & & & $0.870 .17^{*}$ & 0.80 \\
\hline FL + SMT (infl. gap) & $0.67(0.08)$ & $3.24 \quad(0.91)$ & $0.29 *(0.29)$ & $-1.21(0.65)$ & & & 0.860 .17 & 0.68 \\
\hline $\mathrm{FL}+\mathrm{SMT}+\mathrm{FIR}$ & $\mathbf{0 . 7 1}(0.06)$ & $0.94 \quad(0.64)$ & $0.27 *(0.06)$ & $-0.02(0.37)$ & $0.11 \quad(0.12)$ & & $0.870 .24^{*}$ & 0.34 \\
\hline $\mathrm{FL}+\mathrm{FIR}$ & & $5.47(1.13)$ & $\mathbf{0 . 3 4} *(0.16)$ & $-4.43(0.85)$ & $0.67 \quad(0.36)$ & & $0.630 .00 *$ & 0.55 \\
\hline $\mathrm{FL}+\mathrm{SMT}+\mathrm{REER}$ & $\mathbf{0 . 4 0}(0.12)$ & $3.27(0.67)$ & $\mathbf{0 . 4 1} *(0.10)$ & -1.91 (0.52) & & $-0.03 \quad(0.02)$ & 0.860 .04 & 0.81 \\
\hline $\mathrm{FL}+\mathrm{SMT}+\mathrm{NER}$ & $\mathbf{0 . 6 3}(0.10)$ & $1.98(0.80)$ & $\mathbf{0 . 2 0} *(0.08)$ & $-0.67(0.56)$ & & $-0.06 \quad(0.04)$ & 0.890 .32 & 0.77 \\
\hline $\mathrm{FL}+\mathrm{SMT}+\mathrm{SHI}$ & $\mathbf{0 . 7 6}(0.04)$ & $\mathbf{0 . 8 8}(0.40)$ & $\mathbf{0 . 1 7} *(0.04)$ & $0.40 \quad(0.31)$ & & $0.00 *(0.00)$ & 0.840 .16 & 0.65 \\
\hline $\mathrm{FL}+\mathrm{SMT}+\mathrm{MA}$ & $\mathbf{0 . 6 0}(0.13)$ & $3.40(1.10)$ & $0.41 *(0.09)$ & $0.45 \quad(0.69)$ & & $\mathbf{- 0 . 1 7 * ( 0 . 0 5 )}$ & 0.830 .41 & 0.45 \\
\hline $\mathrm{FL}+\mathrm{SMT}+\mathrm{LTIR}$ & $1.58(0.63)$ & $12.06(6.10)$ & $0.32 *(0.17)$ & $0.23 \quad(1.28)$ & & $-2.25 \quad(1.68)$ & 0.570 .61 & 0.60 \\
\hline
\end{tabular}

Notes: See for Bulgaria. infl. gap - inflation gap (inflation deviation from HP trend value) used instead of inflation rate

\begin{tabular}{|c|c|c|c|c|c|c|c|c|c|c|c|c|c|}
\hline $\begin{array}{l}\text { Latvia } \\
\text { 1999:1-2007:3 }\end{array}$ & $\begin{array}{c}\rho \\
\left(\mathrm{i}_{\mathrm{t}-1}\right)\end{array}$ & & nst.) & $\begin{array}{c}\beta \\
\left(\pi_{\mathrm{t}-1}, \pi_{\mathrm{t}+1} *\right) \\
\end{array}$ & $\begin{array}{r}\gamma \\
\left(, \mathrm{y}_{\mathrm{t}}\right.\end{array}$ & & & $\left.\begin{array}{l}\delta \\
\text { for } \\
t^{\prime}\end{array}\right)$ & \multicolumn{2}{|c|}{$\begin{array}{c}\zeta \\
\left(\mathrm{x}_{\mathrm{t}-1}, \mathrm{x}_{\mathrm{t}}^{*}\right)\end{array}$} & $\mathrm{R}^{2}$ & LB & J-stat. \\
\hline BL & & 6.42 & $(1.82)$ & $0.07(0.25)$ & 1.62 & $(0.55)$ & & & & & 0.54 & $0.58 *$ & 0.39 \\
\hline FL & & 4.39 & $(1.23)$ & $\mathbf{0 . 2 5} *(0.10)$ & 0.82 & $(0.27)$ & & & & & 0.64 & $0.16^{*}$ & 0.28 \\
\hline $\mathbf{F L}+\mathbf{S M T}$ & $\mathbf{0 . 8 5}(0.07)$ & 0.81 & $(0.43)$ & $0.06 *(0.03)$ & 0.44 & $(0.08)$ & & & & & 0.74 & 0.39 & 0.71 \\
\hline $\mathrm{FL}+\mathrm{SMT}+\mathrm{FIR}$ & $\mathbf{0 . 6 2}(0.05)$ & 1.79 & $(0.98)$ & $-0.05 *(0.08)$ & 0.25 & $(0.13)$ & 0.10 & $(0.1$ & & & 0.66 & 0.50 & 0.55 \\
\hline $\mathrm{FL}+\mathrm{FIR}$ & & 4.84 & $(1.90)$ & $\mathbf{0 . 2 1} *(0.10)$ & 0.61 & $(0.36)$ & -0.34 & $(0.7$ & & & 0.64 & $0.10 *$ & 0.38 \\
\hline $\mathrm{FL}+\mathrm{SMT}+\mathrm{REER}$ & $\mathbf{0 . 6 0}(0.06)$ & 2.19 & $(0.68)$ & $-0.04 *(0.07)$ & 0.31 & $(0.09)$ & & & 0.00 & $(0.01)$ & 0.74 & 0.70 & 0.65 \\
\hline $\mathrm{FL}+\mathrm{SMT}+\mathrm{NER}$ & $\mathbf{0 . 6 1}(0.06)$ & 2.39 & $(0.75)$ & $-0.09 *(0.10)$ & 0.31 & $(0.13)$ & & & 0.01 & $(0.02)$ & 0.63 & 0.32 & 0.55 \\
\hline $\mathrm{BL}+\mathrm{SMT}+\mathrm{SHI}$ & $0.71(0.08)$ & 1.37 & $(0.71)$ & $0.00 *(0.06)$ & 0.31 & $(0.07)$ & & & 0.01 & $(0.01)$ & 0.72 & 0.99 & 0.80 \\
\hline $\mathrm{BL}+\mathrm{SMT}+\mathrm{MA}$ & $\mathbf{0 . 6 7}(0.21)$ & 1.19 & (2.19) & $0.07 *(0.24)$ & 0.44 & $(0.31)$ & & & 0.02 & $(0.07)$ & 0.69 & 0.67 & 0.77 \\
\hline BL + SMT + LTIR & $\mathbf{- 0 . 5 8}(0.24)$ & -1.97 & $(0.96)$ & $\mathbf{0 . 4 4} *(0.05)$ & 0.76 & $(0.15)$ & & & 1.46 & $(0.22)$ & 0.63 & 0.15 & 0.76 \\
\hline
\end{tabular}

Notes: See for Bulgaria. We do not report the results of the differenced model because no specification has positive $\mathrm{R}^{2}$. 


\begin{tabular}{|c|c|c|c|c|c|c|c|c|c|c|c|}
\hline $\begin{array}{l}\text { Lithuania } \\
\text { 2000:1-2007:4 }\end{array}$ & $\begin{array}{c}\rho \\
\left(\mathrm{i}_{\mathrm{t}-1}\right)\end{array}$ & \multicolumn{2}{|c|}{$\begin{array}{c}\alpha \\
\text { (const.) }\end{array}$} & \multicolumn{2}{|c|}{$\begin{array}{c}\beta \\
\left(\pi_{\mathrm{t}-1}, \pi_{\mathrm{t}+1} *\right)\end{array}$} & $\begin{array}{c}\gamma \\
\left(y_{t-1}\right)\end{array}$ & $\begin{array}{c}\delta \\
\left(i_{t}^{\text {for }}\right)\end{array}$ & $\zeta$ & $\mathrm{R}^{2}$ & LB & J-stat. \\
\hline $\mathrm{BL}$ & & 2.17 & $(0.76)$ & 0.50 & $(0.23)$ & $0.13(0.34)$ & & & 0.82 & $.03 *$ & 0.47 \\
\hline $\mathrm{FL}$ & & 2.00 & $(0.62)$ & $0.33 *$ & $(0.14)$ & $0.07(0.34)$ & & & 0 . & $.01 *$ & 0.52 \\
\hline $\mathrm{BL}+\varsigma$ & $\mathbf{0 . 5 8}(0.07)$ & 0.90 & $(0.30)$ & 0.20 & $(0.10)$ & $-0.07(0.18)$ & & & 0 . & .10 & 0.51 \\
\hline BL + SMT + FIR & $\mathbf{0 . 4 4}(0.02)$ & -1.08 & $(0.31)$ & -0.10 & $(0.05)$ & $0.21(0.09)$ & $\mathbf{1 . 0 9}(0.12)$ & & 0.97 & 0.05 & 0.73 \\
\hline $\mathrm{BL}+\mathrm{FIR}$ & & -0.84 & $(0.58)$ & 0.10 & $(0.14)$ & $\mathbf{- 0 . 4 4}(0.20)$ & $1.41(0.16)$ & & 0.89 & $0.04 *$ & 0.36 \\
\hline BL + SMT + FIR + REER & $\mathbf{0 . 3 9}(0.02)$ & 0.14 & $(0.44)$ & -0.10 & $(0.01)$ & $\mathbf{0 . 3 0}(0.05)$ & $\mathbf{0 . 6 9}(0.14) 0.11$ & $(0.04)$ & 0.97 & 0.99 & 0.69 \\
\hline $\mathrm{BL}+\mathrm{SMT}+\mathrm{FIR}+$ & & & & & & & & & & & \\
\hline $\mathrm{BL}+\mathrm{SMT}+\mathrm{FIR}+\mathrm{SHI}$ & $\mathbf{0 . 3 3}(0.05)$ & -0.29 & $(0.31)$ & 0.05 & $(0.12)$ & $-0.52(0.52)$ & $\mathbf{0 . 7 1}(0.18) 0.01^{*}$ & $*(0.01)$ & 0.94 & 0.21 & 0.80 \\
\hline $\mathrm{BL}+\mathrm{SMT}+\mathrm{FIR}+\mathrm{MA}$ & $\mathbf{0 . 4 6}(0.02)$ & -1.05 & $(0.75)$ & 0.00 & $(0.08)$ & $\mathbf{0 . 3 4}(0.10)$ & $1.06(0.13) 0.00^{\prime}$ & $*(0.02)$ & 0.97 & 0.30 & 0.90 \\
\hline $\mathrm{BL}+\mathrm{SMT}+\mathrm{FIR}+\mathrm{LTIR}$ & $\mathbf{0 . 7 7}(0.07)$ & -0.27 & $(0.09)$ & -0.03 & $(0.03)$ & $\mathbf{0 . 2 1}(0.01)$ & $\mathbf{0 . 5 6}(0.10)-\mathbf{0 . 1 0}$ & $\mathbf{0}(0.04)$ & 0.9 & 0.16 & 0.87 \\
\hline
\end{tabular}

Notes: See for Bulgaria.

\begin{tabular}{|c|c|c|c|c|c|c|c|c|c|}
\hline $\begin{array}{l}\text { Malta } \\
\text { 2000:4 -2007:4 }\end{array}$ & $\begin{array}{c}\rho \\
\left(\mathrm{i}_{\mathrm{t}-1}\right)\end{array}$ & $\begin{array}{c}\alpha \\
\text { (const.) }\end{array}$ & $\begin{array}{c}\beta \\
\left(\pi_{\mathrm{t}-1}, \pi_{\mathrm{t}+1} *\right) \\
\end{array}$ & $\begin{array}{c}\gamma \\
\left(y_{t-1}\right)\end{array}$ & $\left(\mathrm{i}_{\mathrm{t}}^{\delta}\right)$ & $\begin{array}{c}\zeta \\
\left.x_{t-1}, x_{t}^{*}\right)\end{array}$ & $\mathrm{R}^{2}$ & LB & J-stat. \\
\hline $\mathrm{BL}$ & & $6.43 \quad(1.51)$ & $\mathbf{- 1 . 3 3}(0.57)$ & $1.16(0.23)$ & & & -1 . & $4 *$ & 0.84 \\
\hline FL & & $4.47 \quad(1.18)$ & $0.01 \quad(0.03)$ & $-0.02(0.01)$ & & & 0.93 & $0.20 *$ & 0.48 \\
\hline $\mathrm{BL}+\mathrm{SMT}$ & $\mathbf{0 . 7 9}(0.11)$ & $1.07 \quad(0.48)$ & $-0.14 \quad(0.07)$ & $\mathbf{0 . 0 7}(0.03)$ & & & 0.94 & $0.73 *$ & 0.27 \\
\hline $\mathrm{BL}+\mathrm{SMT}+\mathrm{FIR}$ & $0.57(0.34)$ & $1.59(0.61)$ & $\mathbf{- 0 . 1 8}(0.04)$ & $0.06(0.03)$ & $0.10(0.20)$ & & 0.92 & $0.62 *$ & 0.68 \\
\hline BL + FIR (t-1) & & $1.03(0.14)$ & $\mathbf{0 . 1 2}(0.03)$ & $0.00(0.03)$ & $\mathbf{0 . 7 9}(0.03)$ & & 0.95 & $0.55 * *$ & 0.28 \\
\hline $\mathrm{BL}+\mathrm{SMT}+\mathrm{FIR}+\mathrm{REER}$ & $\mathbf{0 . 7 0}(0.25)$ & $1.56(0.40)$ & $\mathbf{- 0 . 3 2}(0.15)$ & $0.02(0.04)$ & $0.11(0.28) 0.06$ & $6 \quad(0.04)$ & 0.91 & 77 & 0.89 \\
\hline $\mathrm{BL}+\mathrm{SMT}+\mathrm{FIR}+\mathrm{NER}$ & $0.41(0$ & $0.06 \quad(0.53)$ & $0.09 \quad(0.10)$ & $-0.07(0.04)$ & $\mathbf{0 . 6 2}(0.26) 0.05$ & $5 \quad(0.04)$ & 0 & 38 & 0.76 \\
\hline $\mathrm{BL}+\mathrm{SMT}+\mathrm{FIR}+\mathrm{SHI}$ & $0.70(0.34)$ & $0.94 \quad(0.52)$ & $\mathbf{- 0 . 2 0}(0.07)$ & $0.04(0.04)$ & $0.20(0.23) 0.00$ & $0 \quad(0.00)$ & 0.91 & $0.78^{*}$ & 0.82 \\
\hline $\mathrm{BL}+\mathrm{SMT}+\mathrm{FIR}+\mathrm{MA}$ & & - & & & & & & & \\
\hline$\underline{\mathrm{BL}}+\mathrm{SMT}+\mathrm{FIR}+\mathrm{LTIR}$ & $\mathbf{0 . 6 7}(0.27)$ & $1.28 \quad(0.27)$ & $\mathbf{- 0 . 2 1}(0.06)$ & $0.07 \quad 0.04$ & $0.05(0.20) 0.06$ & $6 \quad(0.16)$ & 0.90 & $0.73^{*}$ & 0.61 \\
\hline
\end{tabular}

Notes: See for Bulgaria.

\begin{tabular}{|c|c|c|c|c|c|c|c|c|c|c|c|}
\hline $\begin{array}{l}\text { Poland } \\
\text { 1999:1-2007:3 }\end{array}$ & $\begin{array}{c}\rho \\
\left(\mathrm{i}_{\mathrm{t}-1}\right)\end{array}$ & & & $\begin{array}{r}\beta \\
\left(\pi_{\mathrm{t}-1}, \pi_{\mathrm{t}}\right.\end{array}$ & $\left.t_{t+1} *\right)$ & $\begin{array}{c}\gamma \\
\left(\mathrm{y}_{\mathrm{t}-1}\right)\end{array}$ & $\begin{array}{c}\delta \\
\left(\mathrm{i}_{\mathrm{t}}{ }^{\text {for }}\right)\end{array}$ & \multicolumn{2}{|c|}{$\begin{array}{c}\zeta \\
\left(\mathrm{x}_{\mathrm{t}-1}, \mathrm{x}_{\mathrm{t}}^{*}\right)\end{array}$} & $\mathrm{R}^{2}$ & J-stat. \\
\hline $\mathrm{BL}$ & & 2.16 & $(0.41)$ & 1.99 & $(0.09)$ & $-\mathbf{1 . 2 6}(0.17)$ & & & & 0.760 .00 & 0.48 \\
\hline FL & & 0.56 & $(0.59)$ & 1.87 & $(0.19)$ & $-1.13(0.55)$ & & & & 0.550 .00 & 0.56 \\
\hline $\mathbf{F L}+\mathbf{S M T}$ & $\mathbf{0 . 7 7}(0.02)$ & 0.00 & $(0.11)$ & $0.51 *$ & $(0.07)$ & $-0.13(0.12)$ & & & & 0.980 .90 & 0.26 \\
\hline FL + SMT (infl. gap) & $0.93(0.03)$ & 0.13 & $(0.39)$ & $0.60 *$ & $(0.32)$ & $-0.23(0.38)$ & & & & 0.970 .10 & 0.50 \\
\hline $\mathrm{FL}+\mathrm{SMT}+\mathrm{FIR}$ & $\mathbf{0 . 6 6}(0.08)$ & -2.61 & $(1.62)$ & 0.80* & $(0.18)$ & $-0.82(0.41)$ & $0.82(0.48)$ & & & 0.980 .85 & 0.41 \\
\hline $\mathrm{FL}+\mathrm{FIR}$ & & -0.22 & $(2.56)$ & $0.59 *$ & $(0.16)$ & $0.44(0.25)$ & $\mathbf{3 . 1 0}(0.45)$ & & & $0.970 .22 *$ & 0.55 \\
\hline $\mathrm{FL}+\mathrm{SMT}+\mathrm{REER}$ & $\mathbf{0 . 7 8}(0.02)$ & -0.04 & $(0.22)$ & $0.50 *$ & $(0.07)$ & $-0.15(0.19)$ & & -0.01 & $(0.01)$ & 0.980 .96 & 0.46 \\
\hline $\mathrm{FL}+\mathrm{SMT}+\mathrm{NER}$ & $\mathbf{0 . 7 8}(0.02)$ & 0.03 & $(0.11)$ & $0.47^{*}$ & $(0.07)$ & $-0.15(0.19)$ & & -0.01 & $(0.01)$ & 0.980 .92 & 0.42 \\
\hline $\mathrm{FL}+\mathrm{SMT}+\mathrm{SHI}$ & $\mathbf{0 . 9 3}(0.12)$ & -1.20 & $(1.00)$ & $0.30^{*}$ & $(0.16)$ & $-0.21(0.15)$ & & $0.03 *$ & $(0.02)$ & 0.970 .69 & 0.52 \\
\hline $\mathrm{FL}+\mathrm{SMT}+\mathrm{MA}$ & $\mathbf{0 . 8 0}(0.02)$ & 0.24 & $(0.48)$ & $0.64^{*}$ & $(0.09)$ & $-0.20(0.23)$ & & $-0.06 *$ & $(0.02)$ & 0.970 .41 & 0.95 \\
\hline $\mathrm{FL}+\mathrm{SMT}+\mathrm{LTIR}$ & $0.88(0.10)$ & 0.63 & $(0.85)$ & $0.25^{*}$ & $(0.08)$ & $0.05(0.11)$ & & -0.11 & $(0.23)$ & 0.980 .10 & 0.54 \\
\hline
\end{tabular}

Notes: See for Bulgaria. infl. gap - inflation gap (inflation deviation from HP trend value) used instead of inflation rate 


\begin{tabular}{|c|c|c|c|c|c|c|c|c|c|c|}
\hline $\begin{array}{l}\text { Romania } \\
\text { 1999:4-2007:3 }\end{array}$ & $\begin{array}{c}\rho \\
\left(\mathrm{i}_{\mathrm{t}-1}\right)\end{array}$ & & $\begin{array}{l}\alpha \\
\text { nst.) }\end{array}$ & $\begin{array}{c}\beta \\
\left(\pi_{\mathrm{t}-1}, \pi_{\mathrm{t}+1} *\right) \\
\end{array}$ & $\begin{array}{c}\gamma \\
\left(y_{t-1}\right)\end{array}$ & $\left(\mathrm{i}_{\mathrm{t}}{ }^{\text {for }}\right)$ & $\begin{array}{c}\zeta \\
\left(\mathrm{x}_{\mathrm{t}}\right)\end{array}$ & $\mathrm{R}^{2}$ & LB & J-stat. \\
\hline $\mathrm{BL}$ & & 1.09 & $(1.32)$ & $1.06(0.04)$ & $1.18(0.25)$ & & & 0.95 & 0.00 & 0.42 \\
\hline FL & & 0.56 & $(1.52)$ & $1.29 *(0.05)$ & $0.27(0.22)$ & & & 0.92 & 0.15 & 0.33 \\
\hline FL (infl. gap) & & 7.29 & $(3.29)$ & $-0.37 *(0.76)$ & $0.94(0.25)$ & & & 0.92 & $0.36^{*}$ & 0.43 \\
\hline $\mathrm{FL}+\mathrm{SMT}$ & $1.82(0.45)$ & 1.57 & $(2.40)$ & $-1.43 *(0.67)$ & $0.27(1.12)$ & & & 0.74 & 0.07 & 0.29 \\
\hline $\mathrm{FL}+\mathrm{SMT}+\mathrm{FIR}$ & $0.42(0.22)$ & 1.91 & $(2.47)$ & $\mathbf{0 . 5 7 *}(0.27)$ & $0.39(0.42)$ & $-0.35(0.67)$ & & 0.95 & 0.65 & 0.66 \\
\hline $\mathrm{FL}+\mathrm{FIR}$ & & 21.28 & $(7.38)$ & $0.41 *(0.57)$ & $1.02(0.27)$ & $-4.75(2.28)$ & & 0.90 & 0.02 & 0.69 \\
\hline FL + NER & & 5.57 & $(0.91)$ & 0.66* $(0.04)$ & $-0.18(0.16)$ & & $\mathbf{- 0 . 3 4}(0.07)$ & 0.93 & 0.79 & 0.43 \\
\hline $\mathrm{FL}+\mathrm{REER}$ & & 4.80 & $(1.04)$ & $\mathbf{0 . 9 2} *(0.18)$ & $0.62(0.62)$ & & $-0.16(0.08)$ & 0.91 & 0.31 & 0.61 \\
\hline $\mathrm{FL}+\mathrm{SHI}$ & & -2.26 & $(1.86)$ & $1.87 *(0.18)$ & $\mathbf{3 . 2 9}(0.95)$ & & $\mathbf{- 0 . 0 5}(0.02)$ & 0.80 & 0.02 & 0.91 \\
\hline $\mathrm{FL}+\mathrm{SMT}+\mathrm{MA}$ & & - & - & & & & & & & \\
\hline $\mathrm{FL}+\mathrm{SMT}+\mathrm{LTIR}$ & & - & - & & & & & & & \\
\hline
\end{tabular}

Notes: See for Bulgaria. infl. gap - inflation gap (inflation deviation from HP trend value) used instead of inflation rate

\begin{tabular}{|c|c|c|c|c|c|c|c|c|c|c|c|}
\hline \multirow{2}{*}{$\begin{array}{l}\text { Slovenia } \\
\text { 1999:1-2006:4 } \\
\mathrm{BL}\end{array}$} & \multirow[t]{2}{*}{$\begin{array}{c}\rho \\
\left(\mathrm{i}_{\mathrm{t}-1}\right) \\
\end{array}$} & \multicolumn{2}{|c|}{$\begin{array}{c}\alpha \\
\text { (const.) }\end{array}$} & \multicolumn{2}{|c|}{$\begin{array}{c}\beta \\
\left(\pi_{\mathrm{t}-1}, \pi_{\mathrm{t}+1} *\right) \\
\end{array}$} & \multirow{2}{*}{$\begin{array}{c}\gamma \\
\left(\mathrm{y}_{\mathrm{t}-1}\right)\end{array}$} & \multirow[t]{2}{*}{$\begin{array}{c}\delta \\
\left(\mathrm{i}_{\mathrm{t}-1}{ }^{\text {for }}\right.\end{array}$} & \multicolumn{2}{|c|}{$\begin{array}{c}\zeta \\
\left(\mathrm{x}_{\mathrm{t}-1}, \mathrm{x}_{\mathrm{t}}^{*}\right)\end{array}$} & \multicolumn{2}{|c|}{$\mathrm{R}^{2}$ LB J-stat. } \\
\hline & & 5.75 & $(1.87)$ & 0.36 & $(0.30)$ & & & & & 0.660 .23 & 0.95 \\
\hline FL & & 0.29 & $(1.33)$ & $1.32 *$ & $(0.22)$ & $-0.89(0.80)$ & & & & 0.870 .83 & 0.55 \\
\hline $\mathbf{F L}+\mathbf{S M T}$ & $0.78(0.12)$ & -0.66 & $(0.70)$ & $0.38 *$ & $(0.16)$ & $-0.49(0.38)$ & & & & 0.930 .87 & 0.80 \\
\hline FL + SMT (infl. gap) & $0.97(0.04)$ & 0.08 & $(0.40)$ & $-0.08 *$ & $(0.18)$ & $0.24(0.42)$ & & & & 0.940 .16 & 0.43 \\
\hline $\mathrm{FL}+\mathrm{SMT}+\mathrm{FIR}$ & $0.96(0.16)$ & -3.39 & $(2.19)$ & $0.09 *$ & $(0.12)$ & $-1.26(0.92)$ & $0.91(0.47)$ & & & 0.840 .72 & 0.94 \\
\hline $\mathrm{FL}+\mathrm{FIR}$ & & 3.40 & $(2.48)$ & $0.86^{*}$ & $(0.21)$ & $1.37(0.99)$ & $-0.34(0.61)$ & & & 0.800 .21 & 0.59 \\
\hline $\mathrm{FL}+\mathrm{SMT}+\mathrm{REER}$ & $0.73(0.12)$ & -0.39 & $(0.48)$ & 0.39* & $(0.14)$ & $-0.35(0.27)$ & & 0.06 & $(0.05)$ & 0.930 .93 & 0.87 \\
\hline $\mathrm{FL}+\mathrm{SMT}+\mathrm{NER}$ & $\mathbf{0 . 8 1}(0.11)$ & -0.73 & $(0.61)$ & $0.40 *$ & $(0.15)$ & $-0.41(0.32)$ & & 0.07 & $(0.08)$ & 0.930 .83 & 0.84 \\
\hline $\mathrm{FL}+\mathrm{SMT}+\mathrm{SHI}$ & $0.90(0.12)$ & -0.59 & $(0.92)$ & $0.24 *$ & $(0.13)$ & $-0.51(0.50)$ & & $-0.01 *$ & $(0.00)$ & 0.920 .70 & 0.86 \\
\hline $\mathrm{FL}+\mathrm{SMT}+\mathrm{MA}$ & $0.68(0.16)$ & -0.26 & $(1.03)$ & $0.33 *$ & $(0.14)$ & $-0.20(0.47)$ & & $0.05 *$ & $(0.02)$ & 0.910 .26 & 0.59 \\
\hline $\mathrm{FL}+\mathrm{SMT}+\mathrm{LTIR}$ & $\mathbf{- 0 . 0 3}(0.45)$ & 0.73 & $(0.45)$ & $0.37 *$ & $(0.51)$ & $0.17(0.38)$ & & 0.64 & $(029)$ & 0.900 .03 & 0.93 \\
\hline
\end{tabular}

Notes: See for Bulgaria. infl. gap - inflation gap (inflation deviation from HP trend value) used instead of inflation rate

\begin{tabular}{|c|c|c|c|c|c|c|c|c|}
\hline $\begin{array}{l}\text { Slovakia } \\
\text { 1999:1-2007:3 }\end{array}$ & $\begin{array}{c}\rho \\
\left(\mathrm{i}_{\mathrm{t}-1}\right)\end{array}$ & $\begin{array}{c}\alpha \\
\text { (const.) }\end{array}$ & $\begin{array}{c}\beta \\
\left(\pi_{\mathrm{t}-1}, \pi_{\mathrm{t}+1} *\right)\end{array}$ & $\begin{array}{c}\gamma \\
\left(\mathrm{y}_{\mathrm{t}-1}\right)\end{array}$ & $\left(i_{t}^{\delta}\right)$ & $\begin{array}{c}\zeta \\
\left(\mathrm{x}_{\mathrm{t}}\right)\end{array}$ & $\mathrm{R}^{2} \mathrm{LB}$ & J-stat. \\
\hline $\mathrm{BL}$ & & $5.55(0.86)$ & $-0.08(0.14)$ & $-0.38(0.27)$ & & & 0.940 .20 & 0.58 \\
\hline FL & & $5.05 \quad(0.63)$ & $-0.01(0.11)$ & $-0.33(0.40)$ & & & 0.940 .16 & 0.60 \\
\hline BL + SMT & $\mathbf{0 . 7 9}(0.07)$ & $1.17(0.32)$ & $-0.03(0.07)$ & $-0.25(0.21)$ & & & 0.940 .28 & 0.54 \\
\hline BL + SMT + FIR (EUR) & $\mathbf{0 . 9 0}(0.03)$ & $0.21 \quad(0.41)$ & $\mathbf{- 0 . 1 2}(0.03)$ & $-0.24(0.08)$ & $\mathbf{0 . 2 3}(0.11)$ & & 0.940 .39 & 0.47 \\
\hline $\begin{array}{l}\text { BL + SMT + FIR (EUR) } \\
\text { (infl. gap) }\end{array}$ & $\mathbf{0 . 8 8}(0.02)$ & $0.00 \quad(0.37)$ & $\mathbf{- 0 . 1 5}(0.05)$ & $-0.06(0.05)$ & $0.14(0.07)$ & & 0.950 .95 & 0.67 \\
\hline $\mathrm{BL}+\mathrm{SMT}+\mathrm{FIR}(\mathrm{CZE})$ & $\mathbf{0 . 8 0}(0.04)$ & $\mathbf{0 . 7 1}(0.24)$ & $\mathbf{- 0 . 0 9}(0.04)$ & $\mathbf{- 0 . 1 2}(0.09)$ & $0.24(0.16)$ & & 0.940 .50 & 0.86 \\
\hline $\mathrm{BL}+\mathrm{FIR}$ & & $7.61 \quad(2.96)$ & $\mathbf{- 0 . 2 2}(0.10)$ & $0.66(0.34)$ & $-1.26(0.27)$ & & 0.880 .14 & 0.75 \\
\hline $\mathrm{BL}+\mathrm{SMT}+\mathrm{NER}$ & $\mathbf{0 . 8 2}(0.10)$ & $0.31 \quad(0.43)$ & $-0.08(0.05)$ & $-0.14(0.15)$ & $\mathbf{0 . 3 2}(0.11)$ & $-0.05(0.05)$ & 0.950 .39 & 0.58 \\
\hline $\mathrm{FL}+\mathrm{SMT}+\mathrm{REER}$ & $\mathbf{0 . 8 2}(0.10)$ & $0.30 \quad(0.43)$ & $-0.08(0.06)$ & $-0.14(0.16)$ & $\mathbf{0 . 3 2}(0.11)$ & $-0.05(0.05)$ & 0.950 .38 & 0.58 \\
\hline $\mathrm{FL}+\mathrm{SMT}+\mathrm{SHI}$ & $\mathbf{0 . 8 8}(0.03)$ & $0.38 \quad(0.39)$ & $\mathbf{- 0 . 1 3}(0.03)$ & $-0.34(0.09)$ & $0.24(0.08)$ & $0.00(0.00)$ & 0.940 .29 & 0.56 \\
\hline $\mathrm{FL}+\mathrm{SMT}+\mathrm{MA}$ & $\mathbf{0 . 6 2}(0.17)$ & $0.73 \quad(0.39)$ & $0.03(0.13)$ & $0.58(0.57)$ & $0.95(1.10)$ & $-0.13(0.31)$ & 0.930 .09 & 0.86 \\
\hline $\mathrm{FL}+\mathrm{SMT}+\mathrm{LTIR}$ & $1.31(0.27)$ & $-1.00 \quad(0.62)$ & $0.12(0.08)$ & $-0.46(0.27)$ & $1.03(0.58)$ & $-0.86(0.51)$ & 0.860 .05 & 0.70 \\
\hline
\end{tabular}

Notes: See for Bulgaria. infl. gap - inflation gap (inflation deviation from HP trend value) used instead of inflation rate 


\section{DAVIDSON INSTITUTE WORKING PAPER SERIES - Most Recent Papers}

The entire Working Paper Series may be downloaded free of charge at: www.wdi.umich.edu

CURRENT AS OF $10 / 7 / 09$

\begin{tabular}{|c|c|c|}
\hline Publication & Authors & Date \\
\hline $\begin{array}{l}\text { No. 968: Monetary policy rules and inflation process in open emerging } \\
\text { economies: evidence for } 12 \text { new EU members }\end{array}$ & Bořek Vašíček & Sept 2009 \\
\hline $\begin{array}{l}\text { No. 967: Extending Likages Between Organizational Analysis And Social } \\
\text { Structure: A Case Study Of The Celebrity-Construction Of A Chinese } \\
\text { Marketplace }\end{array}$ & Mark Jacobs & Aug 2009 \\
\hline $\begin{array}{l}\text { No. 966: Chinese state's economic cooperation related investment: An } \\
\text { investigation of its direction and some implications for outward } \\
\text { investment }\end{array}$ & $\begin{array}{l}\text { Sumon Bhaumik and } \\
\text { Catherine Yap Co }\end{array}$ & Aug 2009 \\
\hline $\begin{array}{l}\text { No. 965: Capital inflows, household debt and the boom-bust cycle in } \\
\text { Estonia }\end{array}$ & $\begin{array}{l}\text { Zuzana Brixiova, Laura Vartia } \\
\text { and Andreas Worgotter }\end{array}$ & July 2009 \\
\hline No. 964: Labour Market Felxibility in Estonia: What More Can be Done? & Zuzana Brixiova & July 2009 \\
\hline $\begin{array}{l}\text { No. 963: Market Globalization by Firms from Emerging Markets \& Small } \\
\text { Countries: An Application of the Neoclassical Trade Model }\end{array}$ & Tamir Agmon & July 2009 \\
\hline $\begin{array}{l}\text { No. 962: Central Bank Communication and Exchange Rate Volatility: A } \\
\text { GARCH Analysis }\end{array}$ & $\begin{array}{l}\text { Roman Horvath and Radovan } \\
\text { Fiser }\end{array}$ & July 2009 \\
\hline $\begin{array}{l}\text { No. 961: On the influence of oil prices on stock markets: } \\
\text { Evidence from panel analysis in GCC countries. }\end{array}$ & $\begin{array}{l}\text { Christophe Rault and Mohamed } \\
\text { El Hedi Arouri }\end{array}$ & June 2009 \\
\hline $\begin{array}{l}\text { No. 960: Oil Prices \& Stock Markets: What Drives What in the Gulf } \\
\text { Corporation Council Countries? }\end{array}$ & $\begin{array}{l}\text { Christophe Rault and Mohamed } \\
\text { El Hedi Arouri }\end{array}$ & June 2009 \\
\hline $\begin{array}{l}\text { No. 959: Trade Specialisation And Economic Convergence: } \\
\text { Evidence From Two Eastern European Countries }\end{array}$ & $\begin{array}{l}\text { Christophe Rault, Guglielmo } \\
\text { Caporale, Robert Sova \& } \\
\text { Anamaria Sova }\end{array}$ & June 2009 \\
\hline $\begin{array}{l}\text { No. 958: Inflation differentials in the Euro area and their determinants } \\
\text { - an empirical view }\end{array}$ & $\begin{array}{c}\text { Juan Ignacio Aldasoro \& Václav } \\
\text { Žd'árek }\end{array}$ & April 2009 \\
\hline No. 957: Infrastructure and growth: Empirical evidence & $\begin{array}{c}\text { Balazs Egert, Tomasz } \\
\text { Kozluk and Douglas Sutherland }\end{array}$ & April 2009 \\
\hline $\begin{array}{l}\text { No. 956: Infrastructure investment in network industries: The role of } \\
\text { incentive regulation and regulatory independence }\end{array}$ & Balazs Egert & April 2009 \\
\hline $\begin{array}{l}\text { No. 955: The impact of monetary and commodity fundamentals, macro } \\
\text { news and central bank communication on the exchange rate: } \\
\text { Evidence from South Africa }\end{array}$ & Balazs Egert & April 2009 \\
\hline $\begin{array}{l}\text { No. 954: "Family" ownership, tunneling and earnings management: } \\
\text { A review of the literature }\end{array}$ & $\begin{array}{l}\text { Sumon Bhaumik and Andros } \\
\text { Gregoriou }\end{array}$ & $\begin{array}{c}\text { March } \\
2009\end{array}$ \\
\hline $\begin{array}{l}\text { No. 953: Impact of Foreign Direct Investments on Industrial Productivity: } \\
\text { A Subnational Study of India }\end{array}$ & Krishna C. Vadlamannati & $\begin{array}{l}\text { March } \\
2009\end{array}$ \\
\hline $\begin{array}{l}\text { No. 952: Determinants of Exchange Rate Practices in the MENA } \\
\text { Countries: Some Further Empirical Results }\end{array}$ & Sfia, M. Daly and Mouley Sami & Jan 2009 \\
\hline No. 951: An Analytic Approach To Selecting A Nonprofit & $\begin{array}{l}\text { Andrés Ramírez and } \\
\text { Hakan Saraoglu }\end{array}$ & Jan 2009 \\
\hline $\begin{array}{l}\text { No. 950: Anthropometry of Love } \\
\text { Height and Gender Asymmetries in Interethnic Marriages }\end{array}$ & Michèle Belot and Jan Fidrmuc & Jan 2009 \\
\hline No. 949: IS THE COST OF LIVING IN RUSSIA REALLY THAT LOW? & Konstantin Gluschenko & Dec 2008 \\
\hline $\begin{array}{l}\text { No. 948: Banking Market Liberalization and Bank Performance: the Role } \\
\text { of Entry Modes }\end{array}$ & Ngoc-Anh Vo Thi & Jan 2009 \\
\hline $\begin{array}{l}\text { No. 947: The Monetary Union: The Decade Ahead. } \\
\text { The Case of Non-Member States }\end{array}$ & Daniel Daianu and Laurian Lungu & Jan 2009 \\
\hline No. 946: Currency Substitution: A Case Of Kazakhstan (2000:1-2007:12) & $\begin{array}{l}\text { Mesut Yilmaz, Yessengali } \\
\text { Oskenbayev \& Kanat Abdulla }\end{array}$ & Jan 2009 \\
\hline
\end{tabular}

